\title{
EARTH OBSERVATIONS FROM DSCOVR EPIC INSTRUMENT
}

\author{
Alexander Marshak, Jay Herman, Adam Szabo, Karin Blank, Simon Carn, \\ Alexander Cede, Igor Geogdzhayev, Dong Huang, liang-Kang Huang, \\ Yuri Knyazikhin, Matthew Kowalewski, Nickolay Krotkov, Alexei Lyapustin, \\ Richard McPeters, Kerry G. Meyer, Omar Torres, and Yuekui Yang
}

\section{The calibration and products produced by the Earth Polychromatic Imaging Camera on board Deep Space Climate Observatory are discussed.}

T he Deep Space Climate Observatory (DSCOVR) was launched on 11 February 2015 to a sun-Earth first Lagrange point (L1) orbit, approximately 1.5 million $\mathrm{km}$ from Earth toward the sun. Its mission is to provide continuous solar wind measurements for accurate space weather forecasting and to observe the continuously full, sunlit disk of Earth from a new and

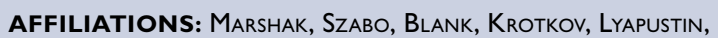
McPeters, Meyer, Torres, ANd YANG—NASA Goddard Space Flight Center, Greenbelt, Maryland; HeRMAN-University of Maryland, Baltimore County, Baltimore, Maryland; CARN-Michigan Technological University, Houghton, Michigan; CEDE-Goddard Earth Sciences Technology and Research, Greenbelt, Maryland; GeOgDZHAYEV - Columbia University, New York, New York; D. HUANG and L.-K. HuANG-Science Systems and Applications, Inc., Lanham, Maryland; KNYAZIKHIN-Boston University, Boston, Massachusetts; KoWALEWSKI-Universities Space Research Association, Greenbelt, Maryland CORRESPONDING AUTHOR: Alexander Marshak, alexander. marshak@nasa.gov

The abstract for this article can be found in this issue, following the table of contents.

DOI:10.II75/BAMS-D-17-0223.I

In final form 16 March 2018

C2018 American Meteorological Society

For information regarding reuse of this content and general copyright information, consult the AMS Copyright Policy. unique vantage point. The DSCOVR mission is a joint venture between National Oceanic and Atmospheric Administration (NOAA), National Aeronautics and Space Administration (NASA), and the U.S. Air Force. NOAA is operating the spacecraft and performs operational space weather forecasting using the DSCOVR solar wind plasma and interplanetary magnetic field measurements. The Air Force provided the SpaceX Falcon 9 launch vehicle. NASA built the spacecraft, performed on-orbit checkout, and operates the two Earth-facing science instruments-the Earth Polychromatic Imaging Camera (EPIC) and the National Institute of Standards and Technology Advanced Radiometer (NISTAR). This paper is limited to applications related to the EPIC instrument.

EPIC consists of a $30-\mathrm{cm}$ aperture Cassegrain telescope with a $0.62^{\circ}$ field of view (FOV), which encompasses Earth, having a nominal size of $0.5^{\circ}$ at the L1 vantage point. Light entering the Cassegrain telescope passes through a field-lens group, then a filter wheel, and finally is focused on a hafniumcoated 2,048 $\times 2,048$ pixel charge-coupled device (CCD) with sensitivity to ultraviolet (UV), visible, and near-infrared (NIR) wavelengths. The filter wheel contains 10 narrowband filters from 317.5 to $779.5 \mathrm{~nm}$ that were designed to obtain products similar to Total Ozone Mapping Spectrometer (TOMS; e.g., Herman et al. 1997) and Moderate Resolution Imaging 
Spectroradiometer (MODIS; e.g., King et al. 1992). During the refurbishment phase, prior to launch, changes were made that significantly improved EPIC capabilities. The primary changes were a significant reduction of stray light (new filters and field-lens group) and addition of the oxygen $\mathrm{A}$ and $\mathrm{B}$ bands to sense cloud and aerosol heights.

Projected on the three-dimensional (3D) Earth, the sampling size is about $8 \mathrm{~km}$ at nadir (near the center of the image), which effectively increases to $10 \mathrm{~km}$ when EPIC's point spread function is included. To maximize time cadence by reducing transmission time, the images of all wavelength channels, except $443 \mathrm{~nm}$, have been reduced to $1,024 \times 1,024$ pixels. This yields a resolution of $10 \mathrm{~km}$ for the color images, which has been verified by looking at the width of major low-latitude rivers in Brazil and Egypt. Of course, the effective resolution is proportional to the secant of the observing angle measured relative to the normal to the Earth's surface $(10 \mathrm{~km}$ at nadir and $20 \mathrm{~km}$ at $\left.60^{\circ}\right)$. The result for $2 \times 2$ pixel averaging is a spatial resolution at nadir of about $18 \mathrm{~km}$.

The Earth-observing geometry of the EPIC instrument is characterized by a nearly constant scattering angle (angle formed between the incident and scattered-to-satellite sunlight vectors) between $168.5^{\circ}$ and $175.5^{\circ}$. Figure 1 displays the sun-Earth view (SEV) angle that is equal to $180^{\circ}$ minus the scattering angle.

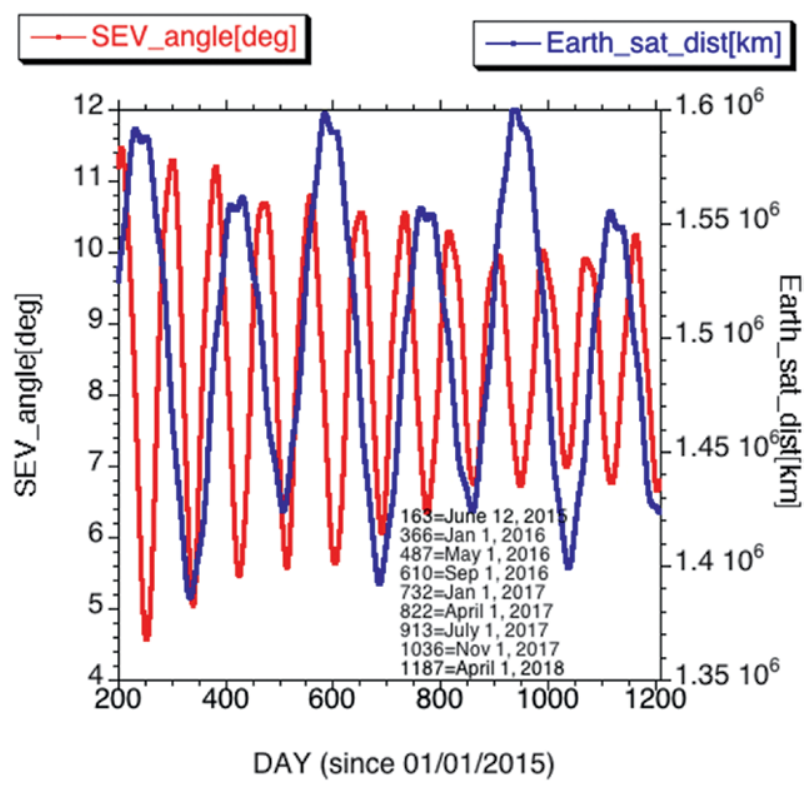

FIG. I. SEV angle (left axis, red curve) and the distance between DSCOVR and Earth (right axis, blue curve) are plotted vs the day since I Jan 2015. Note that SEV $=180^{\circ}$ minus the scattering angle between solar and viewing directions. (SEV usually stands for sun-Earth vehicle, where "vehicle" refers to the satellite.)
The DSCOVR orbit around L1 is smaller than that of the Solar and Heliospheric Observatory (SOHO) and Wind missions, but similar to that of the Advanced Composition Explorer (ACE). It is important to note that the distance between DSCOVR and Earth changes approximately by $2,000-2,500 \mathrm{~km} \mathrm{day}^{-1}$, as part of its nonrepeating Lissajous orbit, or about $0.15 \%$ of its nominal distance of $1.5 \times 10^{6} \mathrm{~km}$.

For the four UV channels, 317.5, 325, 340, and $388 \mathrm{~nm}$, in-flight radiometric calibration is accomplished by comparison to the reflectance values measured by current well-calibrated lowEarth-orbiting (LEO) satellites observing scenes that match in time and observing angles with those from EPIC (Herman et al. 2018; see "Calibration of EPIC UV channels" section). Calibration of the visible and NIR channels is accomplished using well-calibrated measured Earth reflectance values obtained from the Terra and Aqua MODIS LEO satellite observations. Lunar reflectance data are used to help calibrate the two wavelength channels sensitive to the Earth's oxygen absorption (oxygen B and A bands: 687.75 and $764.0 \mathrm{~nm}$ ) relative to their adjacent reference channels 680 and $779.5 \mathrm{~nm}$. The details of these calibration procedures are described in the "Calibration" section, below.

There are natural and enhanced color EPIC images provided daily online (at https://epic.gsfc.nasa.gov). The natural color images were created using the bands from EPIC that are within the human visual range. They have been color, contrast, and brightness adjusted to represent what a human eye would perceive. The redgreen-blue (RGB) ratios of the enhanced color images were processed to emphasize land features. In addition, the Rayleigh molecular scattering and attenuation of solar light by ozone was subtracted. The calculations accounted for Earth's spherical geometry.

While MODIS on Terra and Aqua cross the equator at 1030 and 1330 local time (LT), respectively, DSCOVR EPIC provides measurements of the sunlit face of Earth from sunrise to sunset. Figure 2 illustrates the key difference between the L1 (EPIC) and LEO (MODIS) observations, where the EPIC's observation of Africa is at 1056 UTC. Since Terra crosses the equator at $1030 \mathrm{LT}$, the western part of the left image has a more similar cloud structure with EPIC (middle) than their eastern parts. For Aqua crossing the equator at $1330 \mathrm{LT}$, the eastern part of the right (MODIS) and middle (EPIC) images are more alike than their western parts.

The paper structure is as follows. The next section discusses EPIC calibration starting from raw data, then the geolocation algorithm for level-1 


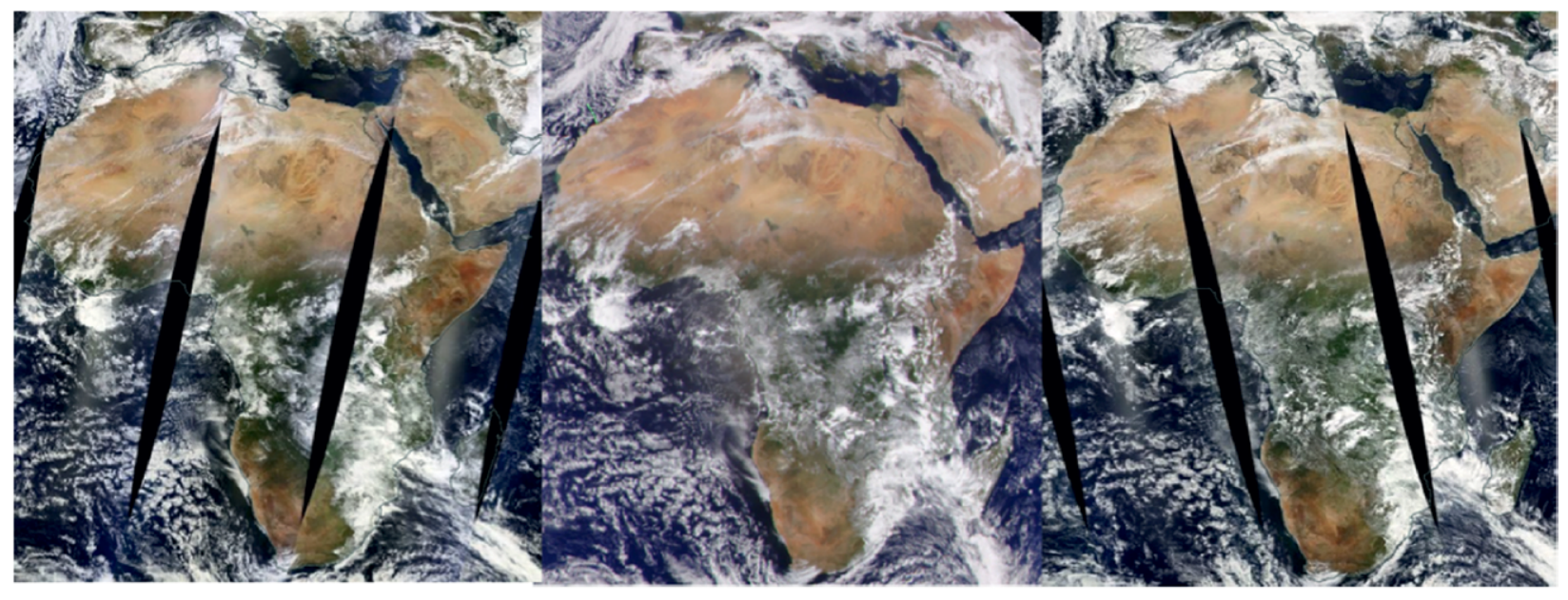

MODIS Terra

EPIC 10:56 GMT

MODIS Aqua

\section{0:30 equatorial crossing time}

13:30 equatorial crossing time

FIG. 2. DSCOVR EPIC “enhanced" image of (center) Africa taken at I056 UTC 22 Mar 2016. (left) MODIS Terra and (right) MODIS Aqua 2,330-km-wide swaths of the same area taken on the same day. Note that West Africa follows UTC while East Africa is UTC $+3 \mathrm{~h}$. Terra crosses the equator at 1030 LT so that the western swath of the left panel (Terra) resembles the cloud structure on the left part of the EPIC image. Since Aqua crosses the equator at $1330 \mathrm{LT}$, the eastern Aqua swath part of the right (Aqua) and middle (EPIC) panels are alike. Also note that the adjacent swaths of the MODIS examples are approximately $100 \mathrm{~min}$ apart.

data, and finally calibration of all EPIC channels converting engineering units of counts per second into reflectance. The third section describes level-2 products. First, there are ozone $\left(\mathrm{O}_{3}\right)$ and Lambert equivalent reflectivity retrievals; then sulfur dioxide $\left(\mathrm{SO}_{2}\right)$ for volcanic eruptions and aerosol products, including atmospheric correction, are discussed. Description of cloud and vegetation level-2 products completes this section. The fourth section reports on expected and unexpected capabilities of EPIC observations. Finally, the fifth section summarizes the results.

CALIBRATION. Raw EPIC data calibration. Before the raw EPIC data (counts per second) can be used for imagery and quantitative applications, a number of preprocessing steps must be taken. Level-0 EPIC data are converted to level-1A "corrected count rates" by correcting for detector, electronics, and opticsinduced effects. The major steps in the conversion from level-0 to level-1A are 1) subtracting the dark offset and dark rate signals; 2) correcting electronics signal-dependent nonlinearity; 3) correcting thermal dependence of the EPIC sensitivity; 4) normalizing by the image integration time; 5) "flat fielding" in order to remove pixel-to-pixel sensitivity differences, vignetting, and etaloning effects; and 6) correcting stray-light effects to account for light that should be going to a particular pixel but instead is scattered to other pixels. The dark offset correction utilizes overclock pixels (Habibi 2017) present in each image, and the dark rate correction is based on analysis of weekly in-flight shutter-closed dark rate measurements. EPIC nonlinearity, temperature sensitivity, and stray-light corrections have been derived from prelaunch test data. The EPIC flat-field correction is based on preflight test data and updated using analysis of in-flight terrestrial observations taken over the first year of science operations. Finally, for level-1B data, the radiometric calibration factors for each wavelength channel are determined in terms of EPIC counts per second conversion to reflectance units (Geogdzhayev and Marshak 2018; Herman et al. 2018).

Geolocation algorithm for level-IA and level-IB data. EPIC image geolocation is a process that calculates the per-pixel latitude and longitude location for each wavelength's image. This includes both the astronomical calculations to relate the scene to the instrument, as well as heuristical calculations to correct errors beyond the spacecraft instrumentation accuracy and achieve pixel-to-coordinate accuracy, as well as pixel-to-pixel coregistration between images on different filters. There are a number of challenges 
to achieving this correction, such as dealing with the rotation of the Earth due to the 0.5-2-min latency between imaging different wavelengths and correction for spacecraft rotation, jitter, and atmospheric refraction correction, as well as an accurate optical model of the telescope. The process of geolocation and georectification requires the images to be accurately mapped to a 3D model of the Earth.

The level-1A algorithm includes all the calculations required for geolocation on the images in their native format. This uses the ephemerides and other spacecraft information to generate a $3 \mathrm{D}$ view of the Earth in the same aspect as seen from EPIC at L1. A two-dimensional (2D) transformation of the 3D model, as it would appear on the CCD, is obtained using an instrument optical and model calculation. This $2 \mathrm{D}$ transformation in turn provides the perpixel geodetic coordinates, as well as sun and viewing angles. Figure 3 depicts this process.

The level-1B algorithm produces images in which all wavelengths are regridded to the same common grid. This includes correcting the images for changes in the scene due to Earth's rotation, drift in spacecraft pointing, and the spacecraft's own orbital motion. As outlined in Fig. 3, the level-1B algorithm takes the location information generated and maps the EPIC pixels into 3D models, one per band. Each model is then rotated into the same orientation [north up, at a common universal time (UT)] and then projected and redrawn into a $2 \mathrm{D}$ image. The result is all 10 wavelength-band images share the same reference grid so that light for each pixel and wavelength comes from the same Earth scene. This is essential, since most of the science algorithms rely on ratios of different wavelength channels.

There are still residual issues that affect the geolocation accuracy. This includes errors with the star-tracker pointing, accuracy of the telescope optical model, image time stamps, and effects of atmospheric refraction. Work is currently underway that treats these additional corrections to further improve science products beyond the basic requirements.

Calibration of EPIC UV channels. Since EPIC was launched without an accurate laboratory calibration,

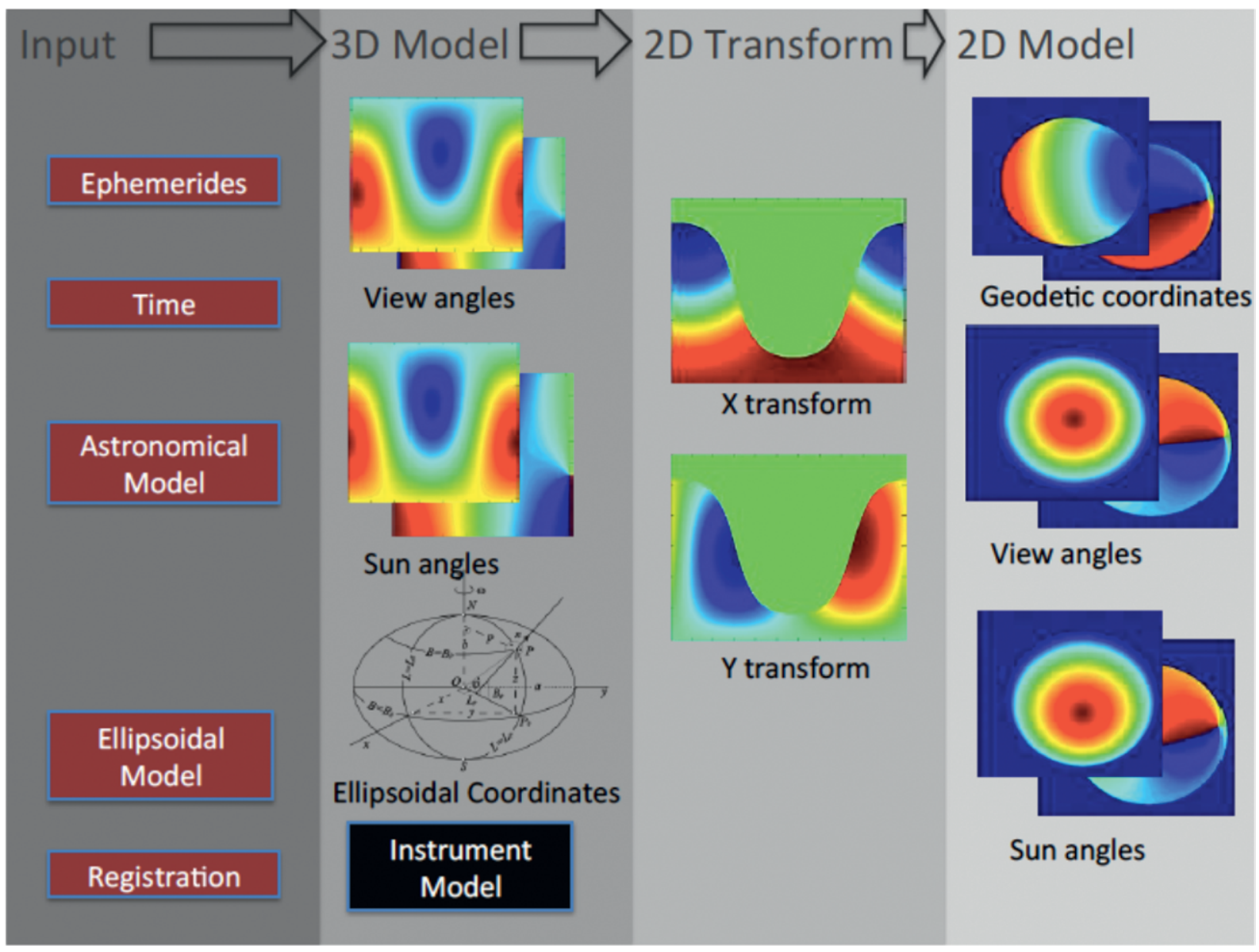

FIG. 3. Schematic diagram of the geolocation process in level-IA algorithm. 
in-flight calibration transfer using other well-calibrated satellites was necessary. There were two suitable LEO satellite instruments: Aura Ozone Monitoring Instrument (OMI; e.g., Torres et al. 2007) and Suomi National Polar-Orbiting Partnership (Suomi NPP) Ozone Mapping and Profiler Suite (OMPS; e.g., Li et al. 2017) that contain similar wavelength channels and are able to observe scenes that closely match in location and angles with those observed by EPIC. Of these, the best calibrated was OMPS, which has an albedo accuracy of $2 \%$ and a wavelength accuracy of better than $1 \%$ (Jaross et al. 2014).

Reflectance calibration was chosen, since the ratio of reflected radiance to the incoming solar flux mostly cancels the strong Fraunhofer line structure. The lack of line structure permits accurate interpolation needed to match the wavelength bands of EPIC. EPIC measures raw counts per second based on permanently fixed exposure times designed to fill the CCD wells to approximately $80 \%$ for the brightest scenes in each of all 10 channels. Comparison with identical OMPS scenes produces EPIC multiplicative albedo calibration coefficients $K_{\lambda}$ (Table 1) to convert counts per second into top-of-atmosphere reflectance $\pi I_{\lambda} / S_{\lambda}$. Here, $I_{\lambda}$ is the radiance measured by OMPS at the top of the atmosphere, and $S_{\lambda}$ is the wavelength-dependent solar flux corrected for the sun-Earth distance. For the UV channels, there is a small secular change of a few percent per year. A more complete discussion is given in Herman et al. (2018).

Calibration of EPIC visible and NIR channels. We used MODIS Aqua and Terra level 1B (L1B) 1-km bands 3 (central wavelength is $469 \mathrm{~nm}), 4(555 \mathrm{~nm}), 1(645 \mathrm{~nm})$, and $2(858.5 \mathrm{~nm})$ reflectance values to infer calibration factors for four EPIC visible and near-IR channels: $443,551,680$, and $780 \mathrm{~nm}$, respectively. For each EPIC pixel, we identified favorable MODIS pixels as follows: i) spatially collocated within $25 \mathrm{~km}$, ii) temporally collocated within $10 \mathrm{~min}$, and finally, iii) having the same scattering angles within $0.5^{\circ}$.

We selected EPIC pixels that had at least 40 MODIS pixels within $25-\mathrm{km}$ radius. Relative standard deviation was then calculated for the matching MODIS and EPIC pixels. In the latter case, a $5 \times 5$ pixel neighborhood was used to calculate the standard deviation. The value of the relative standard deviation was used to select the most homogeneous scenes. Two methods were used to determine the calibration coefficients from the most homogeneous scenes: first, linear regression between EPIC counts and MODIS reflectance values and, second, mean MODIS/EPIC ratio for high MODIS reflectance $(>0.6)$ and small relative standard deviation $(<0.1)$.

The differences in the position and spectral width of the corresponding EPIC and MODIS channels may result in discrepancies when scenes with different spectral signatures are observed by the two instruments. To compensate, we employ spectral-band adjustment factors (SBAFs), which convert MODIS reflectance values to equivalent EPIC reflectances for various surface types. These factors, in the form of linear regression coefficients, were obtained online (from www-angler.larc.nasa .gov/SBAF) and are based on the analysis of Scanning Imaging Absorption Spectrometer for Atmospheric Chartography (SCIAMACHY) hyperspectral data (Scarino et al. 2016). To identify the land-cover type for each matching EPIC pixel, we use a dataset developed by Channan et al. (2014). The land-cover type was identified based on a $0.5^{\circ} \times 0.5^{\circ}$ reprojected version of the global mosaics of the standard MODIS land-cover-type data product (MCD12Q1) in the International Geosphere-Biosphere Programme (IGBP) land-cover-type classification. Separate adjustment factors were used for MODIS Aqua and MODIS Terra data (Geogdzhayev and Marshak 2018).

At the time of this writing, no degradation in the EPIC visible and near-IR bands has been detected, while the UV channels have a very small secular change (Herman et al. 2018). The calibration factors $K_{\lambda}$ for these channels are given in Table 2.

Calibration of the EPIC $\mathrm{O}_{2}$-absorbing bands using lunar observations. To calibrate the $\mathrm{EPIC}_{2}$-absorbing bands, we used EPIC lunar observations at the time of the full moon as seen from the Earth. Lunar reflectance $R_{\lambda}$ does not increase much with a small wavelength change $\Delta \lambda$; a 10 -nm difference in $\lambda$ leads to a difference in $R_{\lambda}$ in the range of $0.0006-0.0013$ or $0.8 \%-1.2 \%$ (e.g., Ohtake et al. 2010, 2013). It follows from this that the difference in moon reflectance between the 
TABLE 2. Calibration factors for three visible channels and one NIR channel.

\begin{tabular}{|lcc|}
\hline$\lambda$ center $(\mathbf{n m})$ & FWHM $(\mathbf{n m})$ & $\boldsymbol{K}_{\lambda}$ \\
\hline $443.0 \pm 1.0$ & 2.6 & $8.340 \times 10^{-6}$ \\
\hline $551.0 \pm 1.0$ & 3.0 & $6.660 \times 10^{-6}$ \\
\hline $680.0 \pm 0.2$ & 1.6 & $9.300 \times 10^{-6}$ \\
\hline $779.5 \pm 0.3$ & 1.8 & $1.435 \times 10^{-5}$ \\
\hline
\end{tabular}

$\mathrm{O}_{2}$ B-band $(688 \mathrm{~nm})$ and the "red" $(680 \mathrm{~nm})$ channels as well as between the $\mathrm{O}_{2}$ A-band $(764 \mathrm{~nm})$ and the near-IR $(780 \mathrm{~nm})$ channels will be within $1.5 \%$.

Since the calibration factors $K_{\lambda}$ for $\lambda=680$ and $780 \mathrm{~nm}$ are assumed to be known from in-flight comparisons between EPIC Earth observations and well-calibrated measured Earth reflectances obtained from the Terra and Aqua MODIS LEO satellite observations (see "Calibration of EPIC visible and NIR channels" section), we can obtain the calibration factors for the $\mathrm{O}_{2}$-absorbing channels at 688 and $764 \mathrm{~nm}$. Indeed, the ratio $F\left(\lambda_{1}, \lambda_{2}\right)$ of the lunar reflectance values measured in counts per second at two neighboring channels $\lambda_{1}$ and $\lambda_{2}$ is very stable (Fig. 4). Thus, the calibration factor $K_{\lambda}$ for $\lambda=688 \mathrm{~nm}$ can be approximated as

$$
\begin{aligned}
K_{688} & =R_{688} / R_{688}^{\text {counts }}=R_{688} /\left[R_{680}^{\text {counts }} F(680,688)\right] \\
& =\left(R_{688} / R_{680}\right) K_{680} / F(680,688) \approx K_{680} / F(680,688) .
\end{aligned}
$$

Similarly to $688 \mathrm{~nm}$, the calibration factor for $764 \mathrm{~nm}$ can be estimated as

$$
K_{764} \approx K_{780} / F(780,764) \text {. }
$$

Here, $R_{\lambda}$ and $R_{\lambda}^{\text {counts }}$ are the values of calibrated reflectance and measured counts per second at wavelength $\lambda$, respectively; $K_{\lambda}$ is the multiplicative calibration coefficient expressed as a conversion from counts per second to reflectance at wavelength $\lambda$ and the ratio $F\left(\lambda_{1}, \lambda_{2}\right)=R_{\lambda_{2}}^{\text {counts }} / R_{\lambda_{1}}^{\text {counts }}$. The calibration factors $K_{\lambda}$ for these channels are given in Table 3.

The calibration factors for all 10 EPIC channels are also publicly available online (at https://eosweb .larc.nasa.gov/project/dscovr/DSCOVR_EPIC _Calibration_Factors_V02.pdf).

PRODUCTS. EPIC ozone and Lambert equivalent reflectivity retrievals. Applying the OMPS-derived calibration to EPIC's counts per second to obtain Earth albedos for each of the UV channels, the reflectances can be used to retrieve total column ozone (TCO), Lambert equivalent reflectivity (LER), aerosol optical depth and absorption, aerosol index (AI), and UV reflectance at the Earth's surface (Herman et al. 2018).

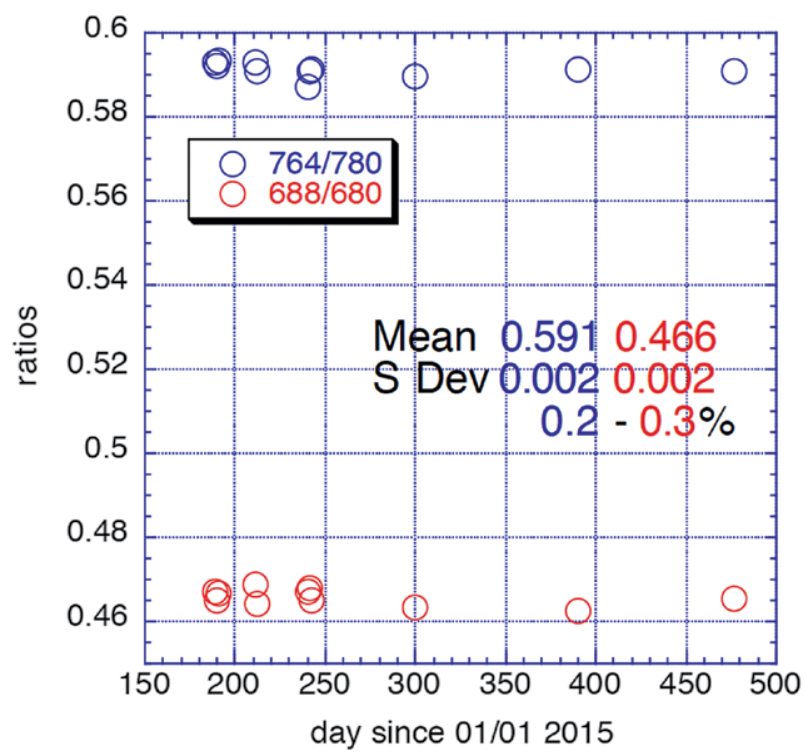

Fig. 4. Moon observations. Ratios of moon reflectance $F$ in counts per second at 688 over $680 \mathrm{~nm}$ and at 764 over $780 \mathrm{~nm}$ channels averaged over moon pixels.

Ozone retrieval requires the use of measured laboratory high-spectral-resolution absorption coefficients (Brion et al. 1993, 1998; Daumont et al. 1992; Malicet et al. 1995). The EPIC-measured reflectance spectra are compared with a set of radiative transfer-derived lookup tables for the EPIC filter transmission functions and for a wide range of ozone values. LER, AI, and ozone are retrieved simultaneously with a maximum resolution of $18 \mathrm{~km}$ at the subsatellite point. A matched pair of ozone and LER images are shown in Fig. 5 for 1658 UTC 21 August 2016.

EPIC ozone has been compared to ozone retrieved from a Pandora spectrometer instrument (PSI) located in Boulder, Colorado (Herman et al. 2015), matched in location and time (UTC) several times per day. The average agreement is $2.1 \% \pm 5.4 \%$ (Fig. 6). An additional comparison (Fig. 7) has been made (Herman et al. 2018) with the assimilated ozone product from the Modern-Era Retrospective Analysis for Research and Applications, version 2 (MERRA-2), based on Microwave Limb Sounder (MLS) and total column ozone from the OMI. All of the structures in the EPIC ozone retrieval are present in the MERRA-2

TABLE 3. Calibration factors for two $\mathrm{O}_{2}$-band channels.

\begin{tabular}{|lcc|}
\hline$\lambda$ center $(\mathbf{n m})$ & FWHM $(\mathbf{n m})$ & $K_{\lambda}$ \\
\hline $687.75 \pm 0.2$ & 0.84 & $2.020 \times 10^{-5}$ \\
\hline $764.0 \pm 0.2$ & 1.02 & $2.360 \times 10^{-5}$ \\
\hline
\end{tabular}


assimilation model ozone but with an average offset of about 3\% [10 Dobson units $\left(1 \mathrm{DU}=2.69 \times 10^{16}\right.$ molecules of $\mathrm{O}_{3}$ per square centimeter)]. Comparisons with MERRA-2 have been made using ozone data from other satellites (Wargan et al. 2017) that have similar offsets.

EPIC $\mathrm{SO}_{2}$ retrievals for volcanic eruptions. Volcanic emissions of sulfur dioxide

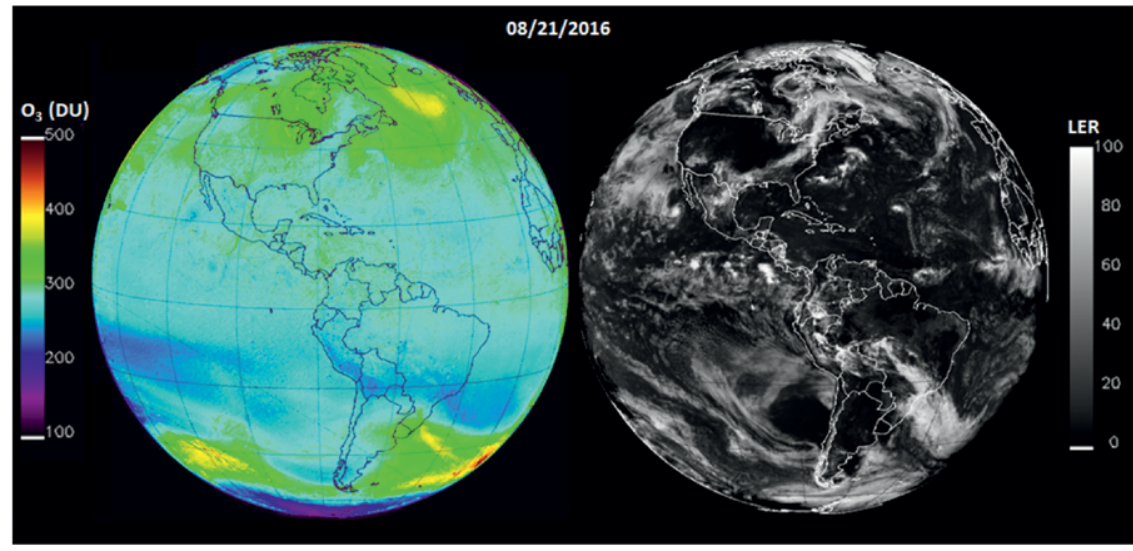

FIG. 5. EPIC-retrieved ozone and LER values at 1658 UTC 21 Apr 2016. The ozone scale is from 100 to $500 \mathrm{DU}$, and the LER scale is from $0 \%$ to $100 \%$. $\left(\mathrm{SO}_{2}\right)$ and ash have been

measured by UV sensors on U.S. and European polarorbiting satellites since the late 1970s (Bluth et al. 1993, 1997; Carn et al. 2003, 2015, 2016; Carn and Krotkov 2016; Guo et al. 2004; Krotkov et al. 1999a,b; Krueger 1983; Krueger et al. 1995, 2000; Li et al. 2017; Pavolonis et al. 2013; Prata 1989; Prata and Prata 2015; Prata and Kerkmann 2007; Prata et al. 2003, 2015; Realmuto 2000; Wen and Rose 1994). These observations permit detection of hazardous volcanic clouds in support of aviation safety management; however, they are generally available only once a day from LEO satellites with a delay of at least 2-3 h. More frequent observations can be crucial in providing timely warnings to mitigate threats to aviation safety. Current geostationary thermal infrared (TIR) imagers including Meteosat Second Generation (MSG) Spinning Enhanced Visible and Infrared Imager (SEVIRI), Geostationary Operational Environmental Satellite 16 (GOES-16) Advanced

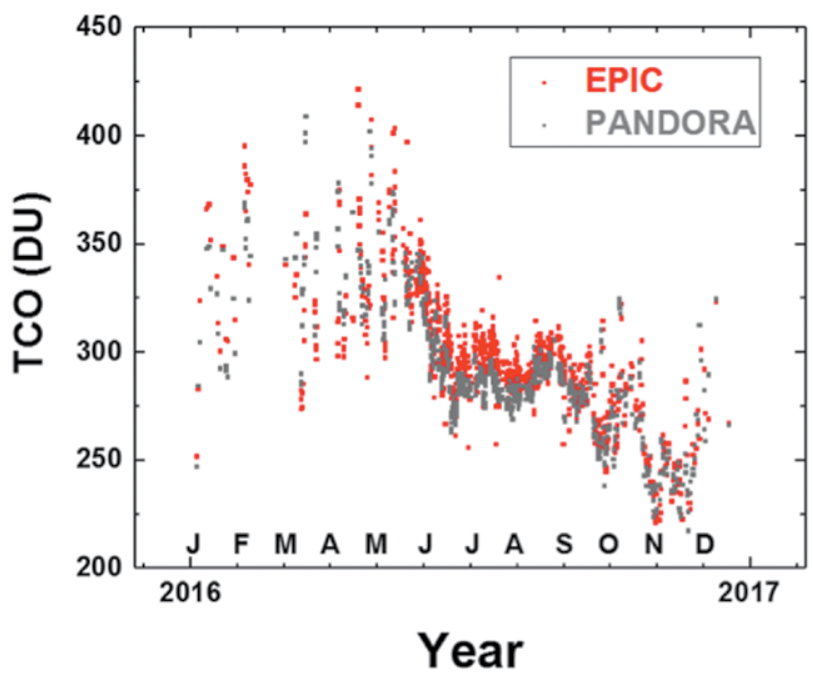

Baseline Imager (ABI), and Himawari-8 Advanced Himawari Imager (AHI) can detect and image volcanic $\mathrm{SO}_{2}$ and ash plumes, taking advantage of highfrequency observations and low latency to provide timely warnings to the public and aviation authorities and operators (Prata 1989; Realmuto 2000; Ackerman et al. 2008; Pavolonis et al. 2013). DSCOVR EPIC provides the first opportunity to observe transient volcanic clouds globally from L1. The unique L1 vantage point offers the potential for multiple daily UV observations of drifting volcanic $\mathrm{SO}_{2}$ and ash clouds globally using a single instrument.

The EPIC volcanic $\mathrm{SO}_{2}$ algorithm is a modified version of the heritage TOMS four-band algorithm, adapted to the EPIC wavelengths. The algorithm uses all four EPIC UV channels $(317,325,340$, and $388 \mathrm{~nm}$ ) to retrieve i) vertical column amounts of $\mathrm{SO}_{2}$ and ii) $\mathrm{O}_{3}$, iii) the LER at $388 \mathrm{~nm}$, and iv) its

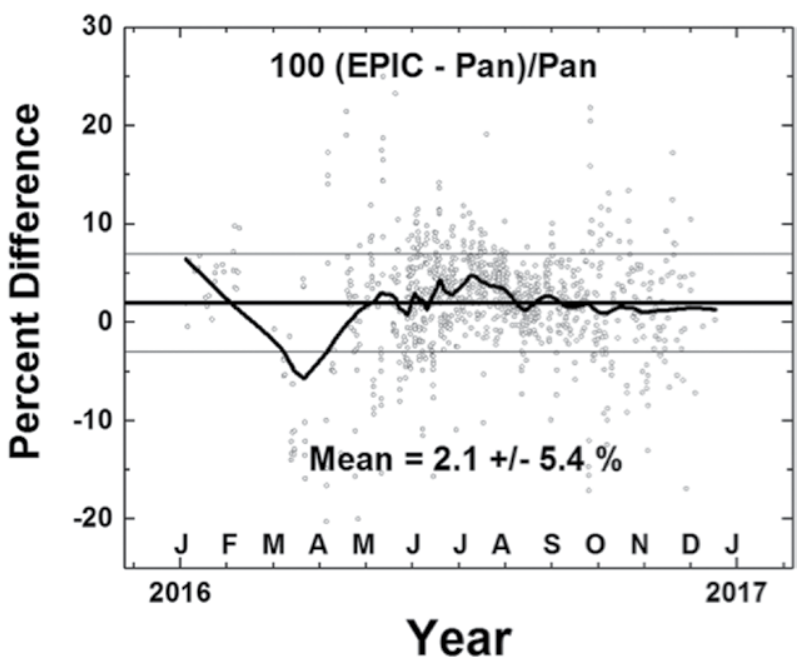

Fig. 6. (left) EPIC ozone data compared to Pandora retrievals at Boulder. (right) Daily (gray circles) and monthly (solid line) average difference between Pandora and EPIC ozone retrievals. 


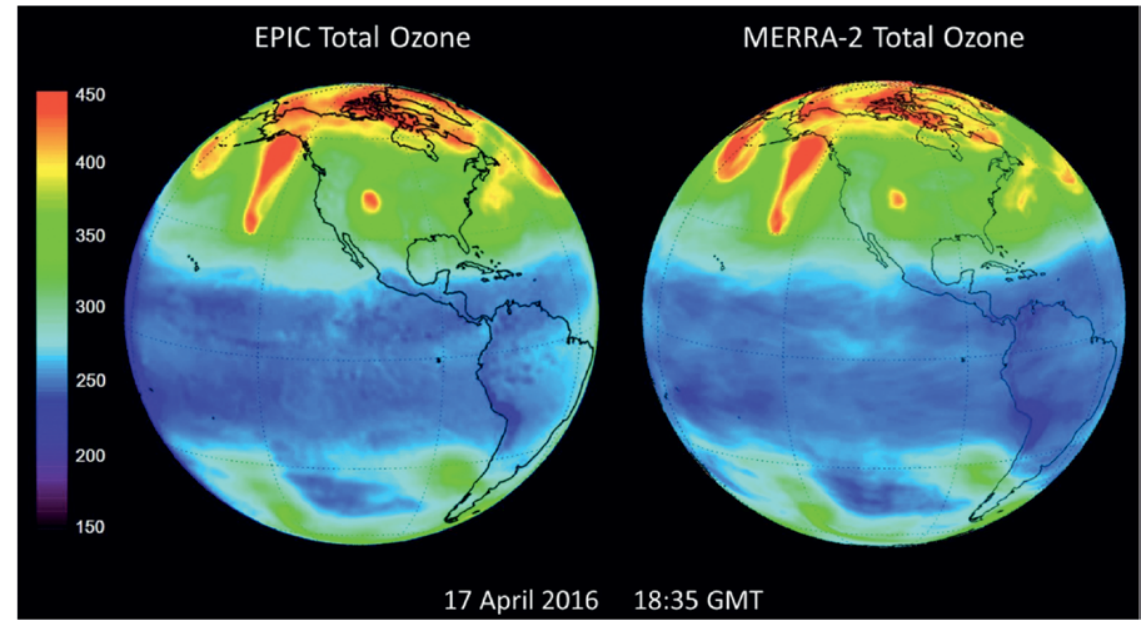

FIG. 7. Comparison of EPIC TCO with the MERRA-2 assimilation ozone model for 17 Apr 2016.

spectral dependence. The algorithm relies on spectral differences in the $\mathrm{SO}_{2}$ and $\mathrm{O}_{3}$ absorption cross sections to simultaneously quantify column amounts of the two gases; $\mathrm{SO}_{2}$ is more absorbing than $\mathrm{O}_{3}$ at the shortest UV channel $(317 \mathrm{~nm})$, whereas $\mathrm{O}_{3}$ is more absorbing than $\mathrm{SO}_{2}$ at the longer channel $(325 \mathrm{~nm})$. The retrieval is performed iteratively for each EPIC pixel. It starts with the climatological value of $\mathrm{O}_{3}$ and zero $\mathrm{SO}_{2}$ and first computes LER at $388 \mathrm{~nm}$. Because the $\mathrm{O}_{3}$ and $\mathrm{SO}_{2}$ absorption are very weak at $388 \mathrm{~nm}$, LER remains fixed during the iterations. The iterations start with climatological values of $\mathrm{O}_{3}$ and zero $\mathrm{SO}_{2}$. The algorithm then retrieves adjustments to the initial guess by matching measured and calculated sun-normalized backscattered UV (BUV) radiances in the shorter-wavelength spectral channels $(317,325$, and $340 \mathrm{~nm}$ ). The sensitivities (Jacobians) associated with linear perturbations in $\mathrm{SO}_{2}, \mathrm{O}_{3}$, and LER are computed for each UV spectral band using precomputed backscattered UV radiances lookup tables that are numerically interpolated to the EPIC viewing geometry at each iteration. This algorithm appears to have adequate sensitivity to detect moderate to large volcanic eruptions from L1 at solar and view zenith angles less than $\sim 70^{\circ}$ (e.g., Fig. 8).

To increase sensitivity to small eruptions, a simplified version of the $\mathrm{SO}_{2}$ algorithm has also been developed. It uses the 317- and 388-nm EPIC channels and an a priori estimate of total ozone. The ozone is regridded and smoothed, which reduces channelto-channel collocation errors. The radiances are normalized accounting for smooth ozone variations but excluding pixels with elevated $\mathrm{SO}_{2}$. This error mitigation results in enhanced sensitivity to small volcanic $\mathrm{SO}_{2}$ clouds.
No large tropical eruptions have occurred during the DSCOVR EPIC mission to date (as of January 2018). However, the sensitivity of EPIC UV radiances to volcanic clouds has been demonstrated by the detection of several mid- to high-latitude eruptions in 2015-17. Figure 8 shows EPIC $\mathrm{SO}_{2}$ retrievals for the high-latitude eruption of Pavlof (Alaska) in March 2016. Comparison with the low-Earth-orbiting Suomi NPP OMPS $\mathrm{SO}_{2}$ data (Fig. 8c) collected at a similar time shows that EPIC clearly detects the proximal volcanic plume where $\mathrm{SO}_{2}$ columns were highest (>10 DU), along with some of the distal plume. Note that the EPIC viewing conditions were not ideal for this eruption, with a relatively high solar zenith angle in Alaska in March; nevertheless, the $\mathrm{SO}_{2}$ cloud was detected in at least two EPIC exposures over approximately a 2-h period on 28-29 March (Figs. 8a,b), with the first observation $\sim 90$ min prior to the Suomi NPP OMPS overpass. The Atmospheric Infrared Sounder (AIRS) on NASA Aqua satellite also detected the Pavlof $\mathrm{SO}_{2}$ emissions, and a coincident AIRS retrieval at $\sim 2330$ UTC 28 March, using the method of Prata and Bernardo (2007), is shown in Fig. 8d. The total $\mathrm{SO}_{2}$ mass of 33 kilotons (kT) measured by AIRS compares favorably with the EPIC retrievals, which detected $\sim 25 \mathrm{kT}$ of $\mathrm{SO}_{2}$.

These EPIC exposures provide unique observations of $\mathrm{SO}_{2}$ cloud transport and have great potential to provide new insight into the evolution of volcanic $\mathrm{SO}_{2}$ emissions, as well as more timely detection and tracking of potentially hazardous volcanic clouds. Forecasting the dispersion of volcanic clouds requires an estimate of the volcanic cloud altitude. The combination of total column $\mathrm{SO}_{2}$ observations from polar-orbiting satellites with trajectory analysis methods has proved useful for estimating volcanic cloud altitudes (Eckhardt et al. 2008; Krotkov et al. 2010; Hughes et al. 2012). Such techniques would be improved by assimilating more frequent observations of volcanic $\mathrm{SO}_{2}$ from EPIC, enabling more rapid estimation of volcanic cloud altitude.

EPIC UV aerosol products. A variety of aerosol and aerosol-related products are derived from EPIC's 


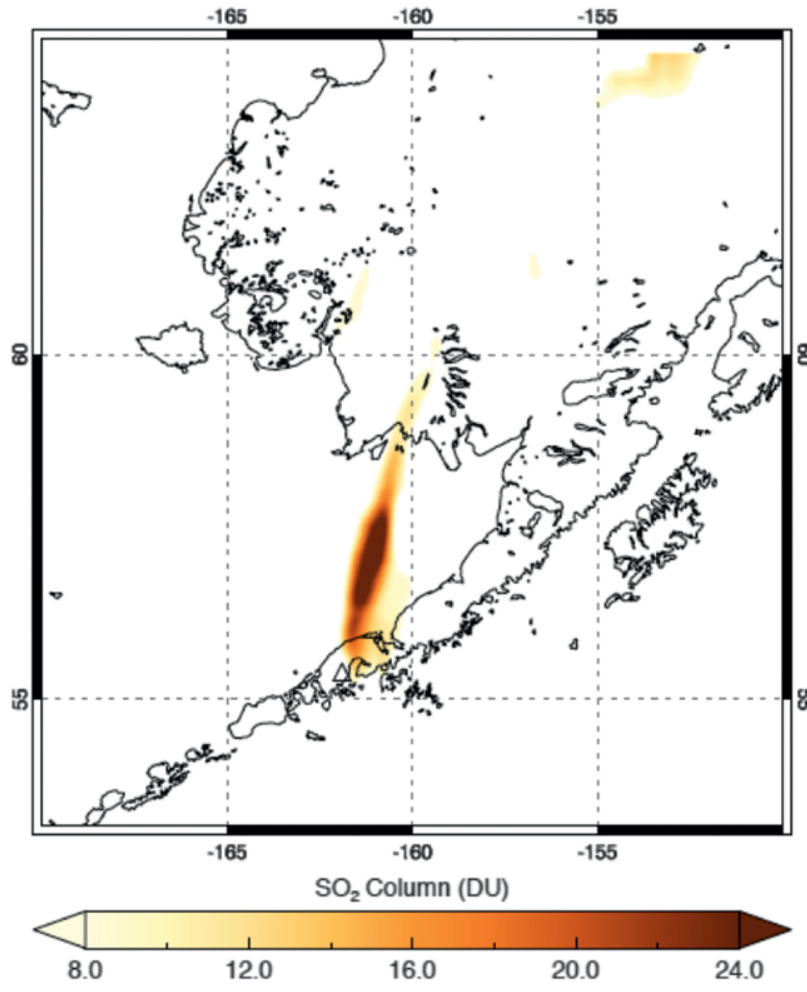

(a)

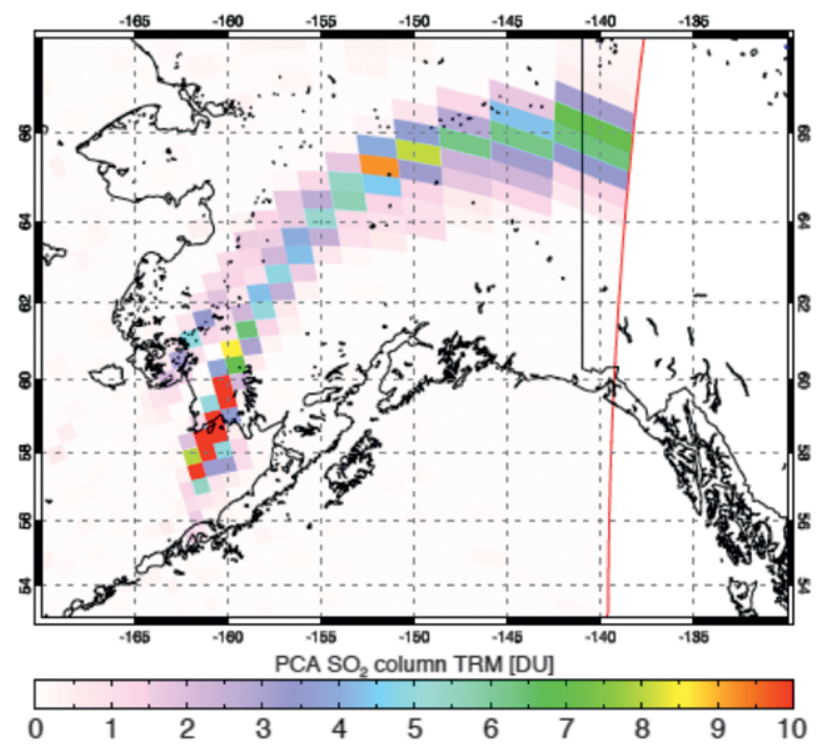

(c)

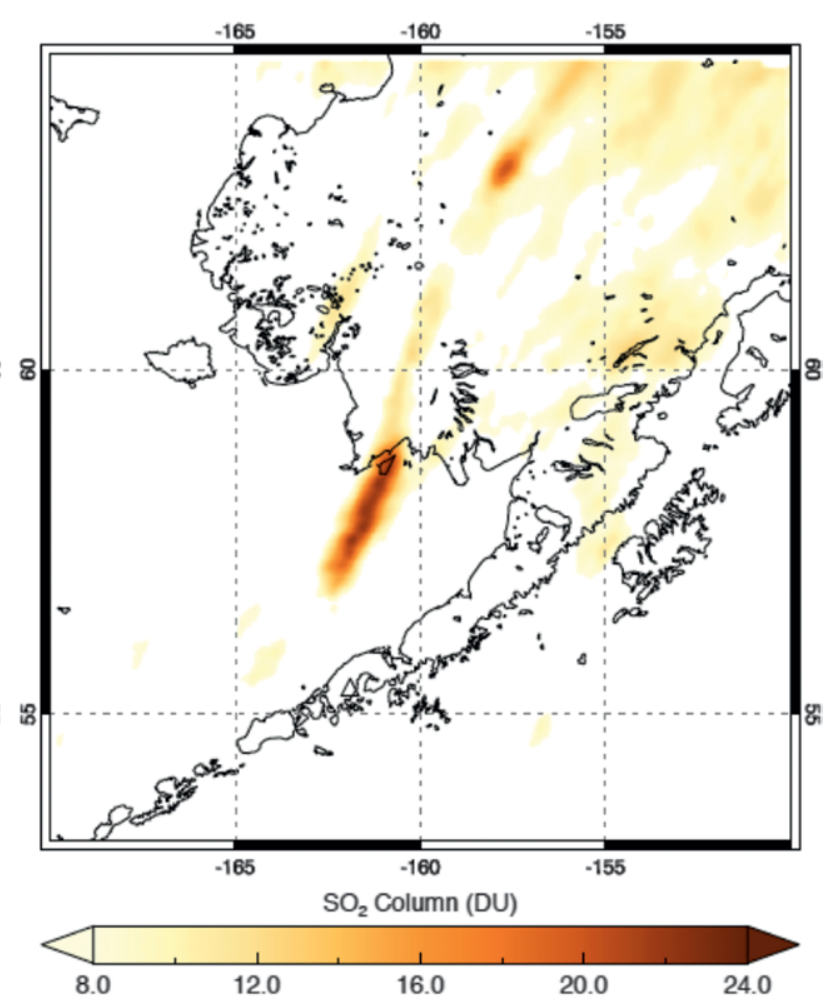

(b)

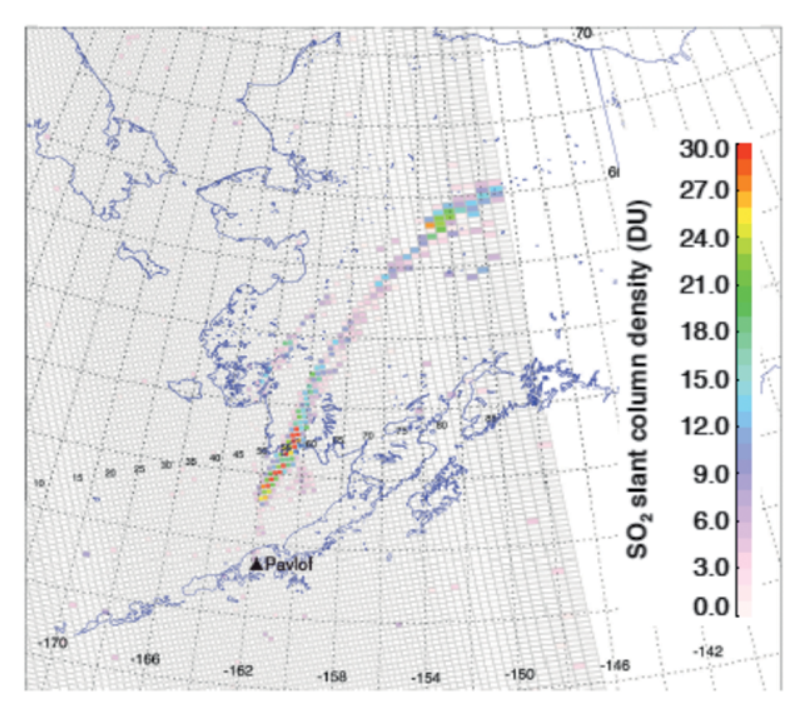

(d)

Fig. 8. $\mathrm{SO}_{2}$ maps for the Mar 2016 eruption of Pavlof volcano (triangle). $\mathrm{SO}_{2}$ in the Pavlof volcanic ash cloud was detected in two EPIC exposures at (a) 2154 UTC 28 and (b) 0008 UTC 29 Mar, (c) Suomi NPP OMPS SO, measurements at 2325 UTC 28 Mar produced using a principal component analysis (PCA) $\mathrm{SO}_{2}$ algorithm assuming a midtropospheric (TRM) volcanic plume located at 5-10-km altitude (Li et al. 2017), and (d) Aqua AIRS $\mathrm{SO}_{2}$ measurements at 2329-2335 UTC 28 Mar.

observations. EPIC extends the multidecadal UV aerosol index (UVAI) record started in 1979 with TOMS (Herman et al. 1997; Torres et al. 1998) and currently available from OMI observations
(Torres et al. 2007). The EPIC UVAI detects carbonaceous aerosols, desert dust particles, and volcanic ash over the oceans and the continents under both clear and partly cloudy conditions, as well as over 
extremely bright backgrounds such as snow/ice surfaces and cloud decks. In addition to the qualitative UVAI product, EPIC observations yield aerosol optical depth (AOD) in the UV-visible range, and near-UV single-scattering albedo for both absorbing and nonabsorbing aerosol types under cloud-free conditions using a modified version of the OMI aerosol algorithm (Torres et al. 2007, 2013). Because of the sensor's coarse spatial resolution, subpixel cloud contamination affects both the frequency of retrievals and the quality of the retrieved aerosol parameters. Figure 9 shows retrievals of UVAI, aerosol optical depth, single-scattering albedo, and absorption optical depth associated with smoke and desert dust events in Africa.

Recently developed retrieval approaches are applied to EPIC observations to obtain the optical depth of aerosol layers above clouds, as well as the cloud optical depth unaffected by aerosol absorption effects (Torres et al. 2012; Jethva et al. 2013). Additionally, radiance measurements in the oxygen $A$ and $B$ bands are used to simultaneously derive the optical depth and the height of elevated desert

dust and smoke aerosol layers over the oceans (Xu et al. 2017).

Atmospheric correction suite. DSCOVR EPIC is contributing to the surface reflectance Earth system data record. The shortcoming of EPIC's rather coarse spatial resolution is compensated by its high (almost hourly) observation rate, which produces up to 8 to 12 images of the same area from dawn to dusk, globally. This provides early morning observations, which are unavailable from MODIS or Visible Infrared Imaging Radiometer Suite (VIIRS), for climatically important tropical regions of the world such as Amazonia where tropical convection generates more clouds in the afternoon. A comparison of statistics between MODIS Terra and Aqua shows about $10 \%$ more clouds from MODIS Aqua with an equatorial overpass time of 1330 LT as compared to MODIS Terra crossing the equator at $1030 \mathrm{LT}$ (Hilker et al. 2015).

The surface products include spectral bidirectional reflectance factors (BRFs; or surface reflectance) and bidirectional reflectance distribution function (BRDF) represented by three parameters of the RossThick Li-Sparse (RTLS; Lucht et al. 2000) model.
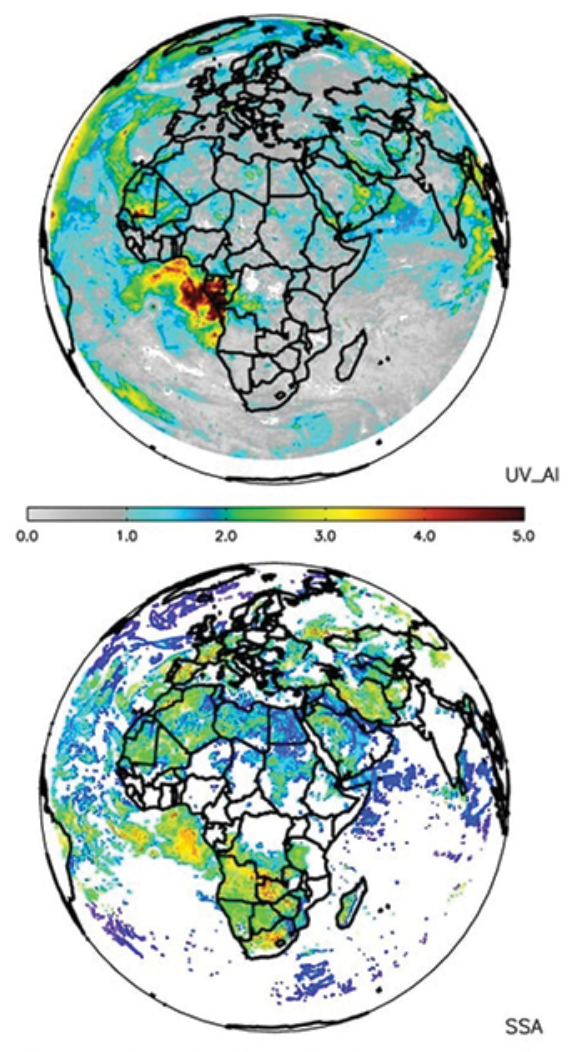

SSA

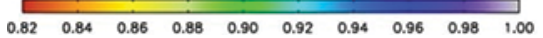

FIG. 9. (top left) EPIC-derived UVAI, (top right) 388-nm AOD, (bottom left) 388-nm single-scattering albedo, and (bottom right) aerosol absorption optical depth derived from observations at 1025 UTC 7 Aug 2016.
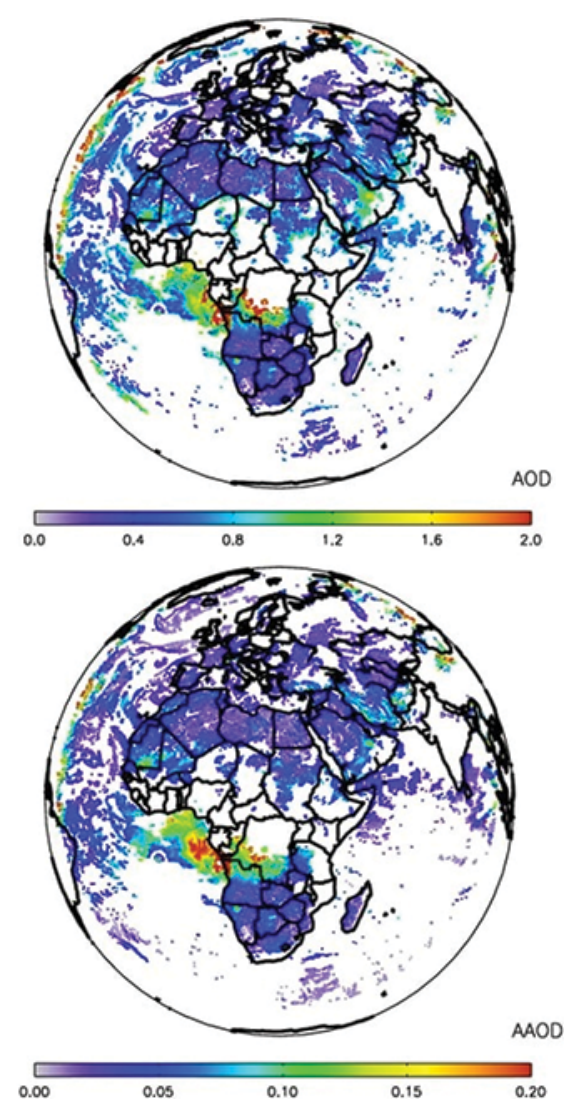
t)

.

(1)

The suite also includes a cloud mask and aerosol optical thickness required for atmospheric correction.

The unique backscattering observation geometry of EPIC will allow us to revisit models of BRDF near the hot spot direction (scattering angle close to $180^{\circ}$ ). So far, only a limited analysis has been conducted based on Polarization and Directionality of the Earth's Reflectances (POLDER) multiangle observations (e.g., Bréon et al. 2002). Such models have a high importance for vegetation monitoring in tropics when geometric variation from a shifting azimuthal plane overlays a seasonal vegetation cycle (e.g., Bi et al. 2016).

Because EPIC differs significantly from MODIS or VIIRS in spectral bands 


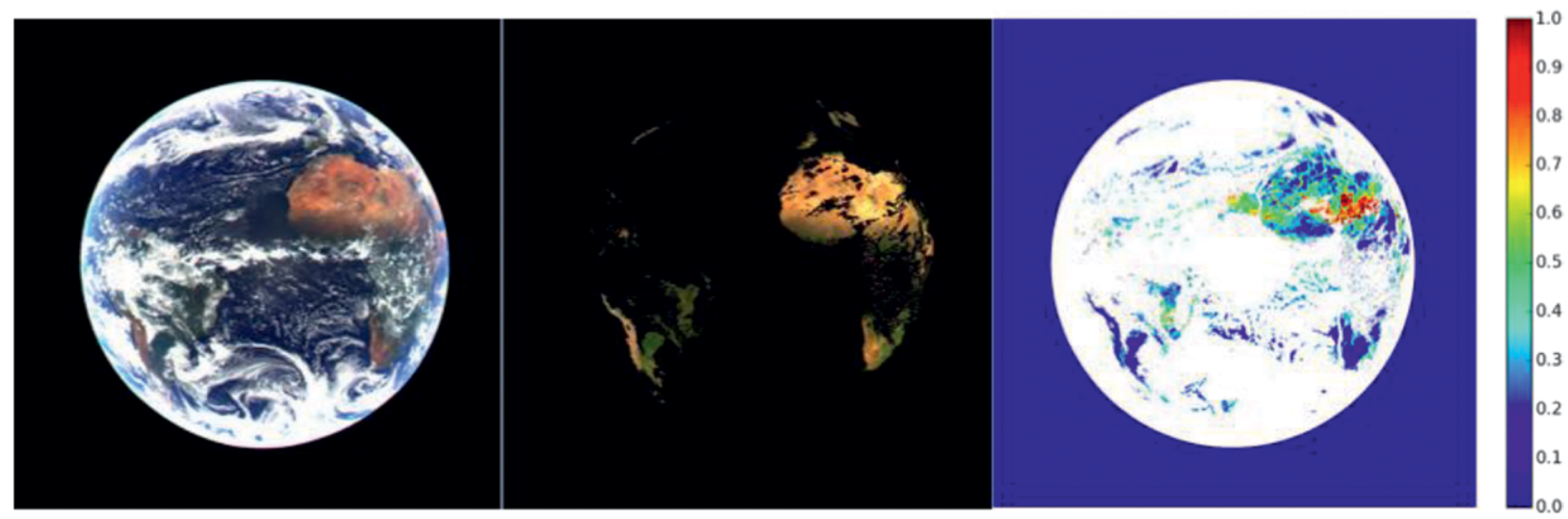

FIG. 10. An example of EPIC data processing at 1312 UTC 27 Mar 2016: (left) EPIC TOA RGB, (center) atmospherically corrected RGB surface reflectance, (right) AOD.

and spatial and temporal resolution, a new processing algorithm is being developed based on elements of NASA Multiangle Implementation of Atmospheric Correction (MAIAC) algorithm originally developed for MODIS (Lyapustin et al. 2011, 2012). The main idea of MAIAC is to take advantage of differences in the space-time variability of atmosphere (aerosols and clouds) and surface to separate their contributions in measured radiance. Such an approach requires observing the same area over time; therefore, EPIC processing starts with gridding observations to a $10-\mathrm{km}$ regular sinusoidal grid. Continuous observations of the same grid cell over time yield multiangle coverage for spectral BRDF retrievals, which then helps cloud detection and aerosol retrievals. MAIAC also characterizes spatial variability between adjacent grid cells under clear skies that helps cloud detection.

The EPIC MAIAC cloud detection employs a set of tests including absolute brightness test, spatial variability test, oxygen A- and B-band test for cirrus detection, and "deviation from expected" test based on our knowledge of spectral surface BRDF, which is translated to an expected top-of-atmosphere (TOA) reflectance. An additional filtering takes place during aerosol retrievals and atmospheric correction, which significantly increases overall data quality.

Aerosol retrieval is based on characterization of the surface spectral reflectance ratios from the time series of EPIC observations using the minimum reflectance method (e.g., Knapp 2002). Following aerosol retrievals, the atmospheric correction stage includes BRDF retrieval and computation of surface reflectance (BRF). The BRDF retrieval uses linear inversion to derive three parameters of the RTLS BRDF model from the multiangle EPIC dataset accumulated from 2 to 3 days of observations over each $10-\mathrm{km}$ grid cell. A preliminary example of atmospheric correction (AC) processing is shown in Fig. 10. It includes the RGB TOA EPIC image at 1312 UTC 27 March 2016 (left), the atmospherically corrected land surface RGB image (middle), and retrieved aerosol optical thickness $\left(\mathrm{AOT}_{0.44}\right)$ both over land and ocean on the right.

EPIC cloud product. Over the years, cloud products from LEO satellites, such as Terra, Aqua, and the NOAA satellites (e.g., Parkinson 2003; Platnick et al. 2017; Heidinger and Pavolonis 2009) and from geostationary-Earth-orbiting (GEO) satellites, such as GOES (e.g., Schmit et al. 2008, 2017), constitute the main global cloud property database. With the launch of DSCOVR, the EPIC instrument provides new opportunities for cloud-related studies, since it covers almost the entire sunlit half of the Earth. Consecutive observations during the day make studying the cloud diurnal cycle on a global scale possible. EPIC cloud products also provide a spatial context for the observations from LEO satellites, because for every LEO observation at daytime, there are always closely collocated EPIC observations. The half-globe synoptic snapshot feature of EPIC makes comparison between synoptic GCM model outputs and observations intuitive (Holdaway and Yang 2016a,b) and helps model validations.

The EPIC level-2 cloud products include cloud mask (CM), cloud effective pressure (CEP), cloud effective height $(\mathrm{CEH})$, and cloud optical thickness (COT). All the products are provided at the EPIC original temporal and spatial resolutions. CEP and $\mathrm{CEH}$ are derived from the oxygen A and B bands, respectively. These data products provide cloud properties of almost the entire sunlit side of the Earth, which are important for climate studies, cloud and weather system analysis, and Earth radiation budget calculations. 
A suite of algorithms for generating the operational EPIC CM, CEP/CEH, and COT products has been developed (Yang et al. 2013; Meyer et al. 2016). 1) The EPIC CM is based on the threshold method; surface is classified into three categories: land, deep water, and snow/ice; for each surface type, two independent tests are applied, and the final CM with confidence level is determined through combining the results from the two tests. 2) For the CEP/ $\mathrm{CEH}$, the mixed Lambertian equivalent reflectivity (MLER) model (e.g., Koelemeijer et al. 2001; Yang et al. 2013) is adopted, which assumes that an EPIC pixel contains two Lambertian reflectors, the surface, and the cloud. This assumption simplifies the radiative transfer equation, and cloud pressure can be retrieved using the oxygen A- and B-band pairs. Since the MLER model does not take into account the effect of photon penetration into clouds, the retrieved cloud pressure is an effective pressure. By incorporating the Goddard Earth Observing System Model, version 5 (GEOS-5), forecasted atmospheric profiles, the CEP is converted to CEH. 3) The EPIC COT product is produced using the operational MODIS cloud retrieval infrastructure (Platnick et al. 2017). The MODIS system provides simultaneous two-channel retrievals of COT and cloud effective radius (CER), and cloud phase retrievals using a variety of spectral tests. However, since EPIC does not have particlesize-sensitive channels, a single-channel retrieval algorithm was developed assuming fixed values for CER (Meyer et al. 2016). In addition, cloud phase determination capability for EPIC is limited; hence, the EPIC COT product provides two retrievals for each cloudy pixel, one assuming liquid phase and the other
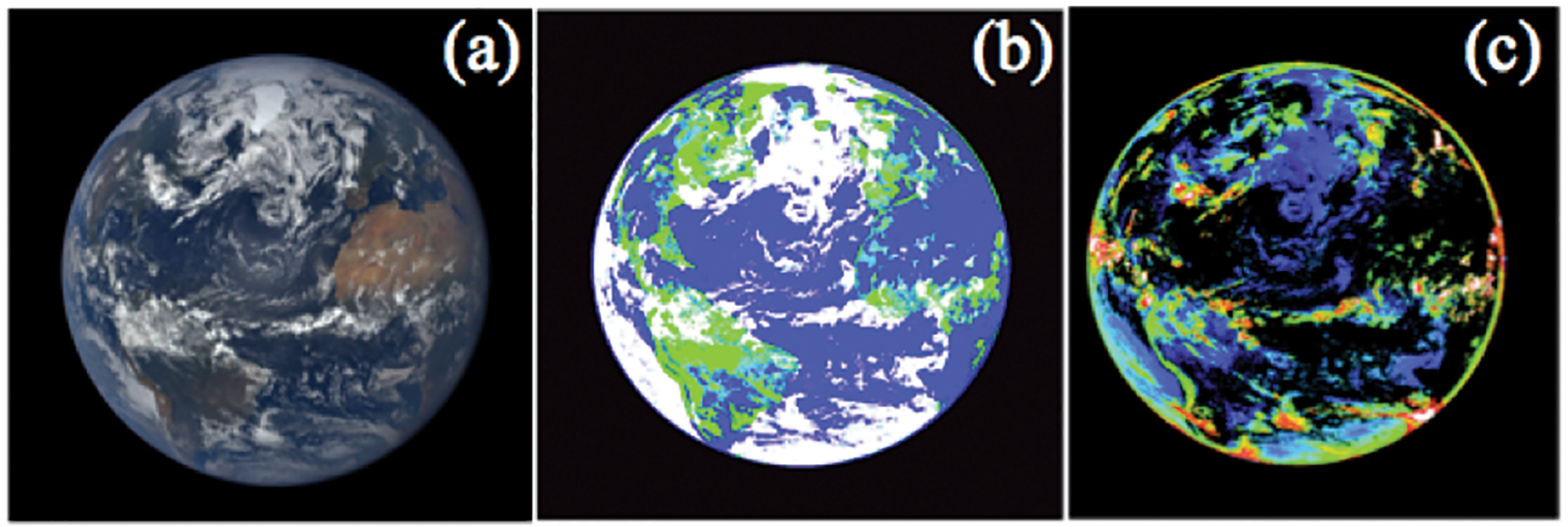

Cloud Eff. Pressure (mb): A-band
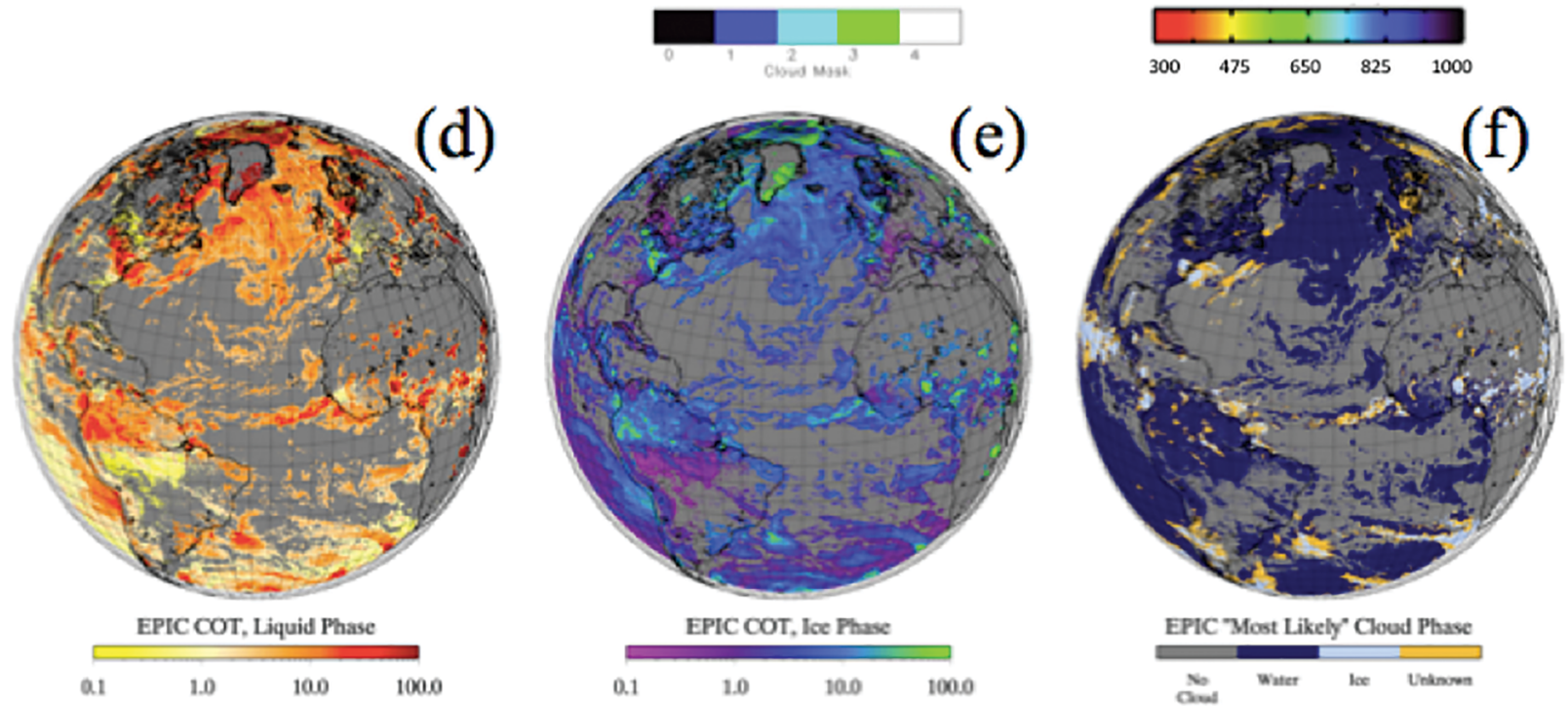

FIG. II. Sample EPIC level-2 cloud products for the observations at I457 UTC 23 Jun 20I6. (a) EPIC RGB image, (b) EPIC cloud mask: I: high-confidence clear, 2: low-confidence clear, 3: low-confidence cloudy, and 4: high-confidence cloudy; (c) oxygen A-band CEP; (d) COT assuming liquid phase; (e) COT assuming ice phase; and (f) most likely cloud phase. Other level-2 cloud products not shown include oxygen B-band CEP and A- and B-band CEH. 
ice phase. A likely cloud phase is also provided based on the CEH. An example of EPIC cloud products is given in Fig. 11. We note that the relatively big EPIC pixel size $(\sim 10 \mathrm{~km}$ at nadir) results in a large number of partially cloudy pixels. This effect is taken into account in the CEP retrieval as the MLER model derives the effective cloud fraction first (Yang et al. 2013). For COT retrievals, coarser spatial resolution results in a smoother retrieval field compared to the fine-resolution MODIS retrievals (Meyer et al. 2016).

EPIC vegetation product. The DSCOVR EPIC science product suite includes vegetation Earth system data record (VESDR) that provides leaf area index (LAI) and diurnal courses of normalized difference vegetation index (NDVI), sunlit LAI (SLAI), fraction of incident photosynthetically active radiation (FPAR) absorbed by the vegetation and Directional Area Scattering Function (DASF). The product at $10-\mathrm{km}$ sinusoidal grid and 65-110-min temporal frequency is generated from the upstream EPIC BRF product ("Atmospheric correction suite" section). Whereas LAI is a standard product of many satellite missions, global diurnal courses of FPAR, NDVI, SLAI (Fig. 12) and DASF are new satellite-derived products. Sunlit and shaded leaves exhibit different radiative response to incident photosynthetically active radiation (400-700 nm; Mercado et al. 2009; Stenberg 1998), which in turn triggers various physiological and physical processes required for the functioning of plants. Leaf area and its sunlit portion are key state parameters in most ecosystem productivity models (Bonan et al. 2003; Chen et al. 2012; Dai et al. 2004; He et al. 2013; Mercado et al. 2009; Norman 1982) and the carbon/nitrogen cycle (Chen et al. 2003; Doughty and Goulden 2008; Wang et al. 2001). DASF provides information critical to accounting for structural contributions to measurements of leaf biochemistry from remote sensing (Knyazikhin et al. 2013).
Theoretical basis of the operational algorithm is documented in Yang et al. (2017) and summarized as follows. The lookup table (LUT) approach implemented in the MODIS operational LAI/FPAR algorithm is adopted. The LUT has been significantly modified. First, its parameterization incorporates the canopy hot spot phenomenon (Fig. 13) and recent advances in the theory of canopy spectral invariants. This allows more accurate decoupling of the structural and radiometric components of the measured BRF, improves scaling properties of the LUT, and consequently simplifies adjustments of the algorithm for data spatial resolution and spectral-band compositions. Second, the stochastic radiative transfer equations are used to generate the LUT for all biome types. The equations naturally account for radiative effects of the three-dimensional canopy structure on the BRF and allow for an accurate discrimination between sunlit and shaded leaf areas. Third, the LUT entries are measurable; that is, they can be independently derived from both below-canopy measurements of the transmitted and above-canopy measurements of reflected radiation fields. This feature makes possible direct validation of the LUT and facilitates identification of its deficiencies and development of refinements.

The BRF of the vegetation reaches its maximum in the backscattering directions (Fig. 13). This is the so-called hot spot effect, that is, a sharp increase in canopy-reflected radiation when scattering direction approaches the direction to the sun (Kuusk 1991; Nilson 1991; Qin et al. 1996; Ross and Marshak 1988). The EPIC sensor therefore sees the brightest portion of the canopy-reflected radiation. This feature allows us not only to directly obtain sunlit leaf area but also estimate how individual leaves reflect solar radiation, which is unique diagnostic information about leaf biochemical constituents (National Research Council 2007; Ustin 2013). Leaf optical properties can be

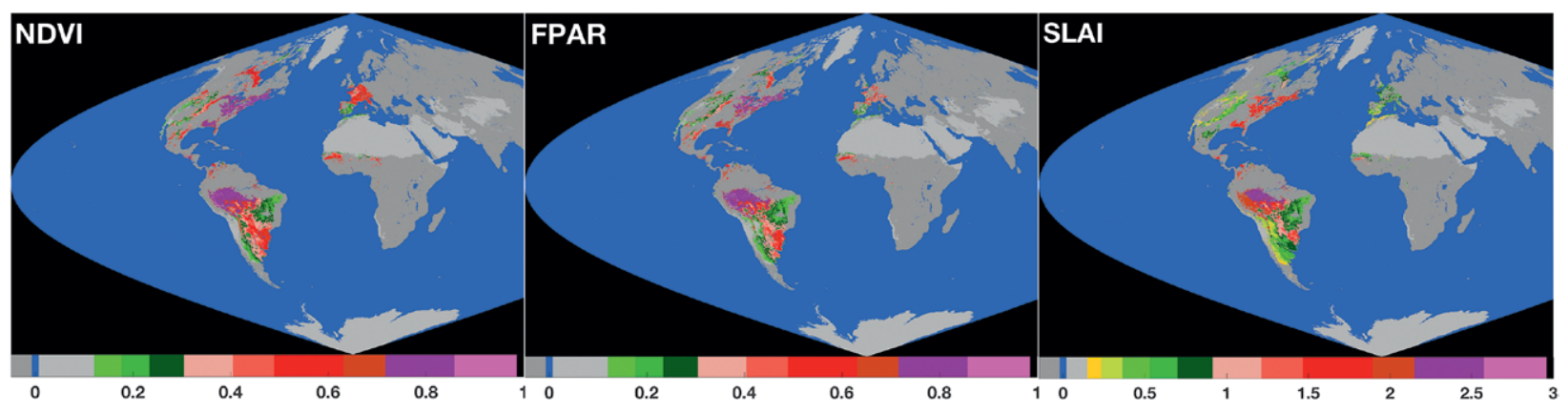

Fig. 12. (left) NDVI, (center) FPAR, and (right) SLAl at 1524:58 UTC 23 Aug 2016. Corresponding EPIC image of the sunlit Earth is shown in Fig. 13. 

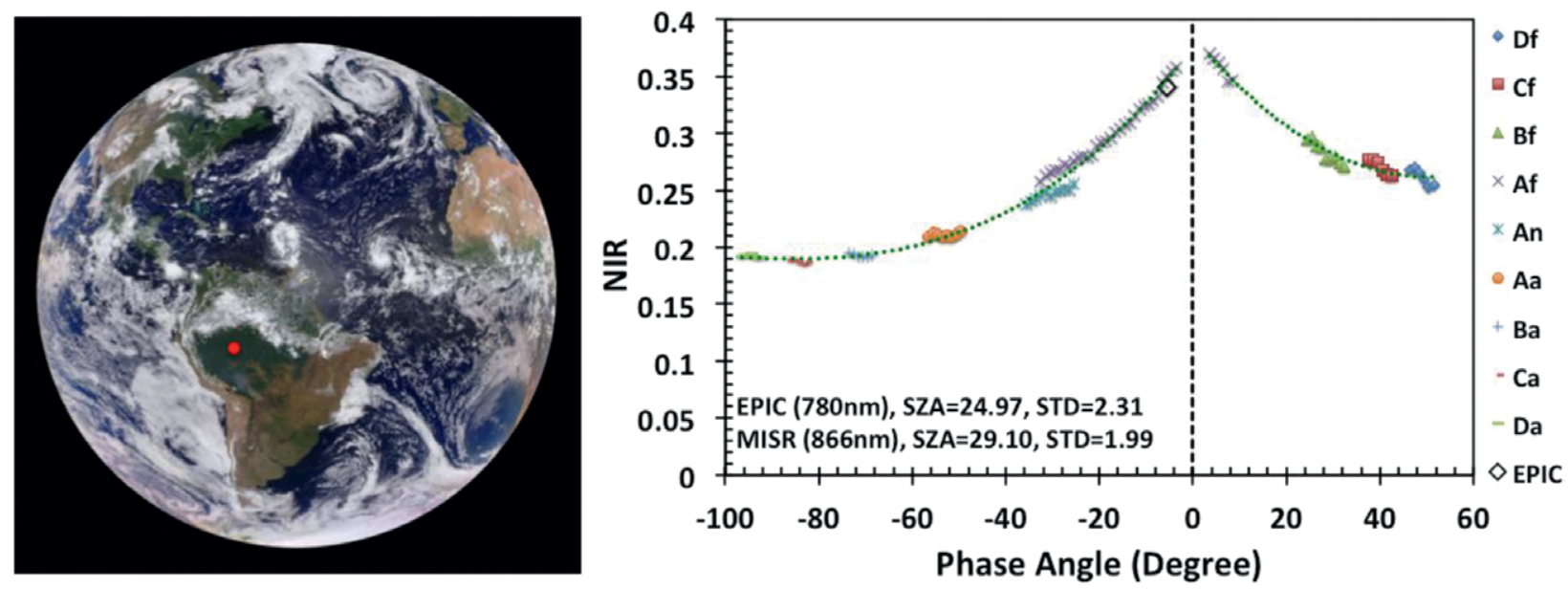

Fig. 13. (left) Enhanced RGB image of the sunlit face of the Earth (http://epic.gsfc.nasa.gov/enhanced) taken at 1524:58 UTC 23 Aug 2016. (right) NIR BRF of an area in Amazonian rain forest (red circle in left panel) derived from Multiangle Imaging SpectroRadiometer (MISR) data (symbols) and EPIC (white square). Horizontal axis shows values of the phase angle (i.e., the angle between directions to the sun and sensor).

described by the scattering coefficient, which is the fraction of the canopy-intercepted radiation that has been reflected from, or diffusely transmitted through, the canopy (Knyazikhin et al. 2013). Figure 14 shows a false-color image (688-551-680 $\mathrm{nm}$ ) of the scattering coefficient derived from DSCOVR EPIC images (Marshak and Knyazikhin 2017). The radiation scattered by the vegetation in backscattering directions is very strong, allowing the EPIC to see green leaves even through optically thin clouds.

\section{EXPECTED AND UNEXPECTED} CAPABILITIES. Use of the oxygen $B$ band for monitoring vegetation. The EPIC NDVI, defined (Tucker 1979 ) as the ratio between the difference and the sum of the NIR $(780 \mathrm{~nm})$ and the red $(680 \mathrm{~nm})$ channels, is used to monitor vegetation dynamics. A useful estimate of vegetation density requires an accurate atmospheric correction. However, it was recently shown (Marshak and Knyazikhin 2017) that if the EPIC $\mathrm{O}_{2}$ $B$ band $(688 \mathrm{~nm})$ is used instead of the conventional red band $(680 \mathrm{~nm})$, the effect of the atmosphere (diffuse radiation) on remote sensing of surface reflectance is reduced, and the residual uncertainties in atmospheric correction can be better tolerated. This is due to two factors: i) the vegetated surface is sufficiently dark at $688 \mathrm{~nm}$, and ii) the $\mathrm{O}_{2}$-absorbing atmosphere substantially reduces multiple scattering. Note that also at the slightly longer wavelength of $688 \mathrm{~nm}$, there is less Rayleigh and aerosol scattering.

To support this statement, the spectral invariant approximation to the BRF of vegetated surface (Knyazikhin et al. 2011; Stenberg et al. 2016; Yang et al. 2017) was used. It was shown that the retrieval of spectrally invariant coefficients (Marshak and Knyazikhin 2017) determined by purely canopy structure is only weakly sensitive to the uncertainties in the spectral properties of the atmospheric optical depth above the canopy. On the other hand, the spectrally varying scattering coefficient at the EPIC green and NIR spectral bands is fully determined by the chlorophyll absorption spectrum and can be estimated from the TOA BRF and the approximated spectrally invariant coefficients (Fig. 14). It was demonstrated (Marshak and Knyazikhin 2017) that the approximated values of the scattering coefficient at 551,688 , and $780 \mathrm{~nm}$ fit well the spectral shape of the "true" scattering coefficient over vegetated land for all atmospheric conditions observed. The spectral signature of the chlorophyll absorption at these wavelengths is unique to green leaves. Consequently, the wavelength-dependent scattering coefficient of the vegetated surface differs significantly from any one of other types of reflecting media, as illustrated in Fig. 14.

Figure 15 illustrates with two NDVIs with 780 and 680 (center panel) and 780 and 688 (right panel) over Africa that the 780 and 688 NDVI better identifies patterns of dense vegetation compared to the 780 and 680 NDVI. This is because without an accurate atmospheric correction the 780 and 688 NDVI is more sensitive to the presence of the chlorophyll than the standard 780 and 680 one.

Detection of oriented ice crystals from 1.5 million km away. Many DSCOVR EPIC images contain 
unexpected bright flashes of light over land not usually seen by other satellites. Figure 16 provides an example of such flashes. Here, we focus on flashes only over land so as not to be confused with glints over ocean water. Marshak et al. (2017) constructed a yearlong time series of flash latitudes, scattering angles, and oxygen absorption to demonstrate conclusively that the flashes over land are specular reflections off tiny ice platelets, floating in air nearly horizontally.

The time series of latitudes of the detected flashes

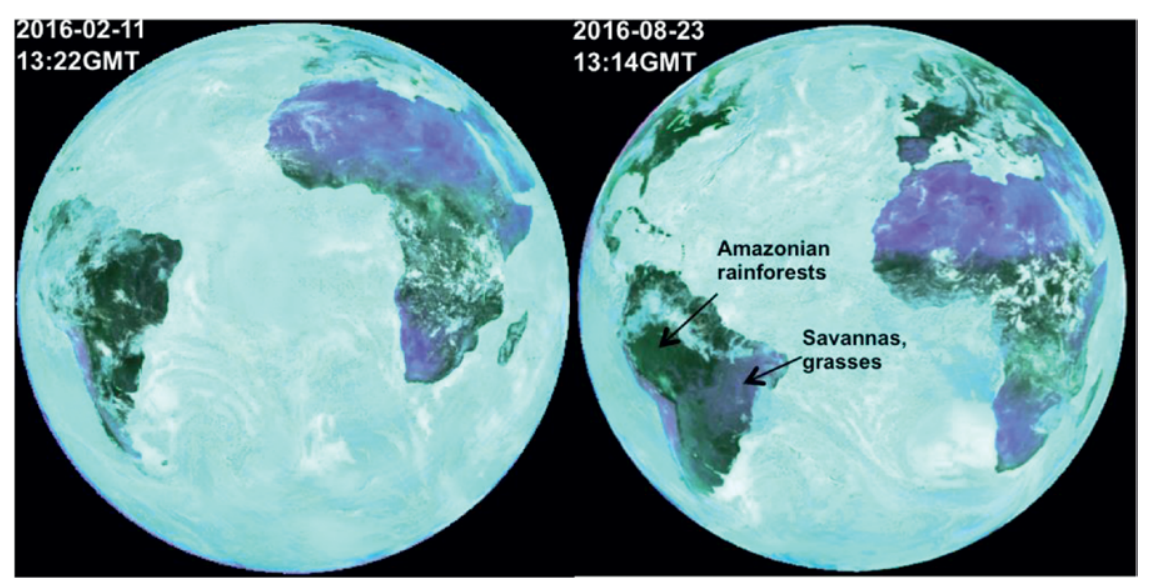

FIG. 14. Vegetation dynamics. False-color image (688-55I-680) of the scattering coefficient derived from DSCOVR EPIC images taken at I322 UTC II Feb and I3I4 UTC 23 Aug 2016 using a simple algorithm documented in Marshak and Knyazikhin (2017). The green color indicates green leaves that EPIC sees through the atmosphere. The images capture changes in savannas from wet (approximately Jun-Sep) and dry (Oct-May) seasons when the area of green leaves increases during the wet season and decreases during the dry season. corresponds to a set of lati-

tudes that permit specular reflection for a given time of year. As the Earth's axial tilt $\left(23.4^{\circ}\right)$ causes local zenith directions to vary, the glints reach their southernmost latitude of $\sim 25^{\circ} \mathrm{S}$ around 22 December and their northernmost latitude of $\sim 25^{\circ} \mathrm{N}$ around 22 June. The detected glints are near the equator around the equinoxes in March and September. The almost complete coincidence of the measured latitudes with the theoretical curve constituted compelling evidence for the ice crystal specular reflection hypothesis.

In addition, using EPIC measurements of absorption by molecular $\mathrm{O}_{2}$ via the ratio of absorbing channel to adjacent nonabsorbing channel reflectances, cloud height was estimated for all detected flashes. Compared with radiative transfer simulations of $\mathrm{EPIC}_{2} \mathrm{~A}$ - and B-band ratios, it was shown that that the glints occur within middle to high clouds that are most likely to contain horizontally oriented ice platelets.

While we are not aware of any deep space or geostationary observations $(36,000 \mathrm{~km})$ of glint off tropospheric ice clouds reported in the literature, atmospheric observations of such specular ice reflections have been made with ground-based lidars (Sassen

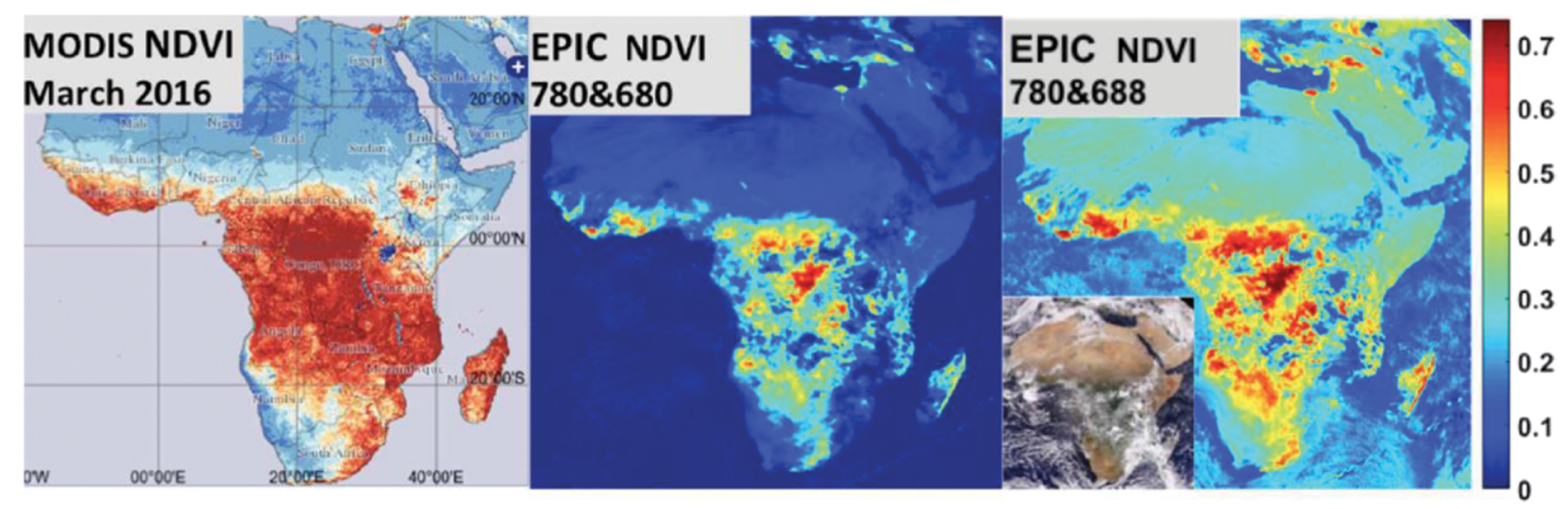

FIG. 15. MODIS and EPIC NDVIs. (left) MODIS Terra surface NDVI composited over Mar 2016 (https://giovanni .gsfc.nasa.gov/giovanni/). EPIC NDVIs at 1052 UTC 22 Mar 2016 calculated with the (center) red and (right) $\mathrm{O}_{2}$ $B$-band channels. The inset in the right panel is the RGB plot. The use of the $\mathrm{O}_{2} B$ band enhances the sensitivity of the TOA NDVI to the presence of vegetation. Note that EPIC data do not have any atmospheric correction or cloud mask. Areas with high MODIS NDVI and very small EPIC NDVI are likely covered by clouds. From Marshak and Knyazikhin (2017). 
and Benson 2001) and by satellites on low-Earth orbit: POLDER polarized measurements (Chepfer et al. 1999; Breon and Dubrulle 2004; Noel and Chepfer 2004) and Cloud-Aerosol Lidar and Infrared Pathfinder Satellite Observation (CALIPSO) lidar returns (Noel and Chepfer 2010). All such cloud glint observations are bounded by an altitude of about $700 \mathrm{~km}$ and have broader angular resolution than EPIC.

Based on in situ measurements of cirrus clouds (e.g., Korolev et al. 2000), tiny hexagonal platelets of ice floating in air in nearly perfect horizontal alignment are likely responsible for the glints observed by EPIC over land. Cirrus clouds permanently cover more than $30 \%$ of the Earth's surface and play a major role in the Earth's radiation budget (Stephens et al. 1990). Most of these clouds are composed of nonspherical ice crystals. The orientation of these crystals is difficult to detect; however, oriented particles create a very strong specular reflection (Yang et al. 2003), and if their concentration is large enough, it can substantially increase cloud albedo compared to randomly oriented crystals.

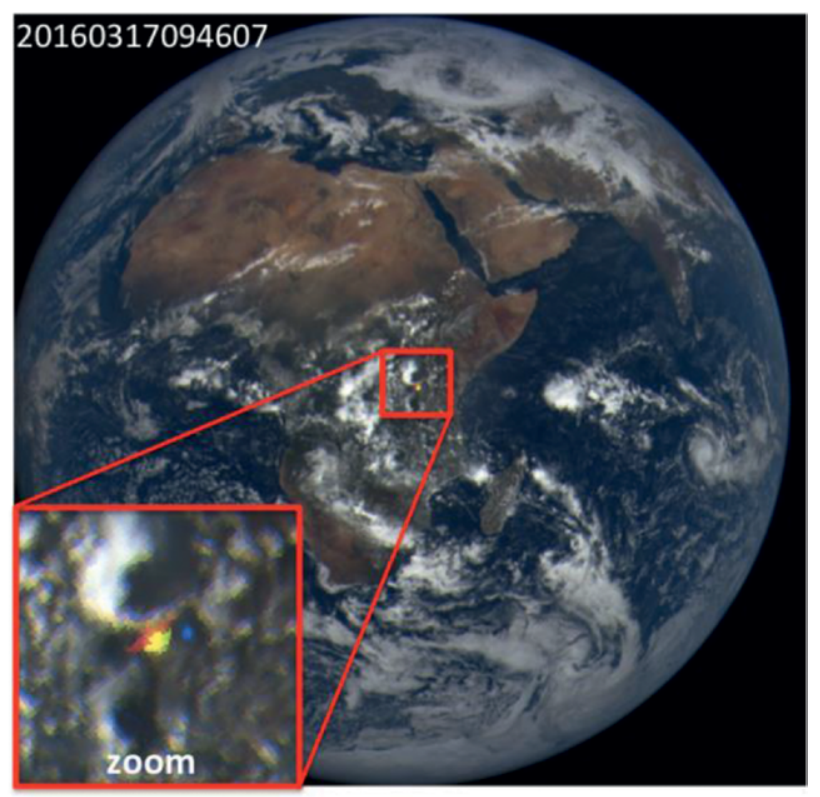

FIG. 16. An example of terrestrial glint. A true-color composite image captured at 0946 UTC 28 Oct 2015 is shown (all EPIC true-color images are available at http://epic.gsfc.nasa.gov). The pixel size is about $10 \times 10 \mathrm{~km}^{2}$, and angular spread is $\sim 3^{\circ} \times 10^{-4}$. A wheel inside EPIC spins color filters, causing a time lag between the component images: $\sim 3 \mathrm{~min}$ between blue $(443 \mathrm{~nm})$ and green $(55 \mathrm{I} \mathrm{nm}), \sim 4 \mathrm{~min}$ between blue and red $(680 \mathrm{~nm})$, resulting in a coloration effect in the imagery. The framed region contains a bright colorful spot discernible by a naked eye and centered at $8.31^{\circ} \mathrm{S}$, $25.5^{\circ} \mathrm{E}$ (magnified in the inset).
EPIC erythemal irradiance. Synoptic ozone and cloud reflectivity and cloud transmission have been determined for most days during the current operating lifetime of DSCOVR. These may be used to estimate the erythemal irradiance at the Earth's surface as a function of latitude, longitude (time of day), and altitude (Herman et al. 2018). The method is based on previous calculations (Herman 2010) applied to polar-orbiting satellites that measured ozone and reflectivity at 1330 LT and then assumed that the same values applied to noon. The noon assumption can be applied to slowly varying ozone, but it is not accurate for estimating the effects of cloud transmission $T$ from rapidly varying cloud cover. This is especially true for local times other than noon. The calculation method outlined here for erythemal irradiance can be easily extended to other processes dependent on a wavelength-dependent action spectrum (Herman 2010). Using the spectrally weighted erythemal action spectrum $A_{\mathrm{ERY}}(\lambda)$, the erythemal irradiance is derived from an integral over UV wavelengths $\lambda$ :

$$
E_{0}(\theta, \Omega, T)=\int_{250}^{400} I(\lambda, \theta, \Omega, T) A(\lambda) d \lambda
$$

For $250<\lambda \leq 298 \mathrm{~nm}, \log _{10}\left(A_{\mathrm{ERY}}\right)=0$,

For $298<\lambda<328 \mathrm{~nm}, \log _{10}\left(A_{\mathrm{ERY}}\right)=0.094(298-\lambda)$, For $328 \leq \lambda<400 \mathrm{~nm}, \log _{10}\left(A_{\text {ERY }}\right)=0.015(139-\lambda)$,

where $E_{0}(\theta, \Omega, T)$ is the erythemal irradiance at sea level from a radiative transfer calculation (Herman 2010). The erythemal weighting function $\log _{10}\left[A_{\text {ERY }}(\lambda)\right]$ is given by the standard fitting function (McKinley and Diffey 1987). At altitude $z$, the calculation of erythemal irradiance $E(\theta, \Omega, z, T)\left(\mathrm{W} \mathrm{m}^{-2}\right)$ is defined in terms of the product $E_{0}(\theta, \Omega, T) \times H(\theta$, $\Omega, z)$, where $H(\theta, \Omega, z)=1+f(\theta, \Omega, z)$. Here, $f$ is the fractional increase of $E_{0}$ as a function of altitude for specified solar zenith angle $\theta$ and ozone amount $\Omega$. The details and computational method are described in Herman (2010) and with extensions for $H(\theta, \Omega, z)$ in Herman et al. (2018).

An example of $E(\theta, \Omega, z, T)$ is shown in Fig. 17a at 1716 UTC 1 April 2016. Local noon is near the center of the image with sunrise to the left (west) and sunset to the right (east). For this date, the sun is overhead just north of the equator, producing very high values of erythemal irradiance $E(\theta, \Omega, z, T)$ corresponding to a UV index (UVI) of 13 at sea level in the Pacific Ocean [UVI $=40 \times E(\theta, \Omega, z, T)$ ]. Higher values $(\mathrm{UVI}=16)$ are seen in the Sierra Nevada in Mexico near $20^{\circ} \mathrm{N}$. This particular day has some small clouds over most of South America except for thick clouds over eastern Argentina. For the erythemal irradiance, the presence of clouds reduces the amount of UV 

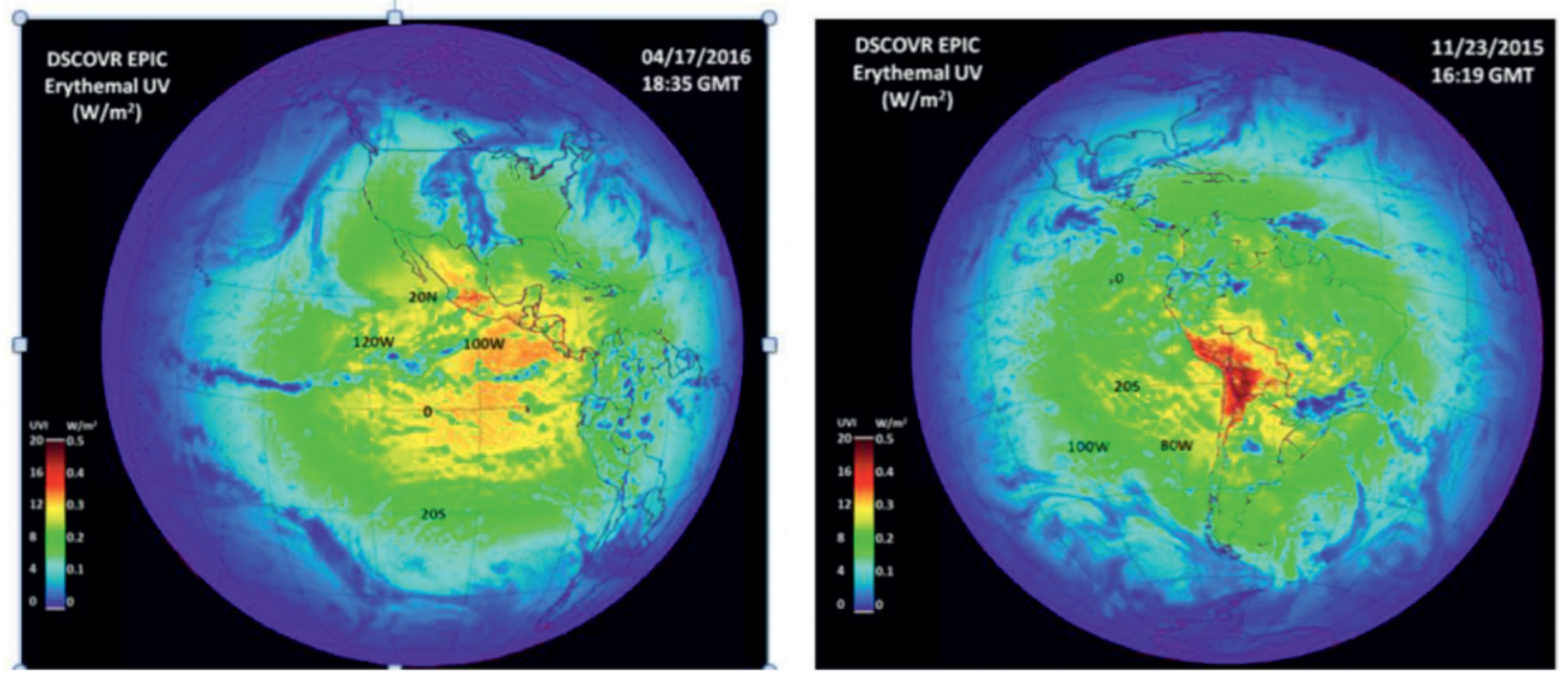

FIG. I7. Erythemal irradiance: (a) I Apr 2016 over Central and South America and (b) 27 Nov 2016 over South America.

reaching the ground (blue color with a UV index of less than 4).

The increase with altitude is much more pronounced during the summer months over the Andes, reaching above $4 \mathrm{~km}$ (over 13,000 ft). Figure 17b shows the large increases with altitude over the Andes for 27 November 2016, with the sun nearly overhead at $20^{\circ} \mathrm{S}$ latitude. Here, the UV index ranges from 16 to 18 , which agrees with previous ground-based measurements in this region (Cede et al. 2002). In the completely clear regions of the Andes, the UV index is even higher than 18 .

SUMMARY. DSCOVR was launched on 11 February 2015 into an L1 orbit, about 1.5 million $\mathrm{km}$ from Earth toward the sun to provide continuous solar wind measurements and to observe the sunlit disk of Earth from a new and unique vantage point. The observation of the rotating sunlit face of the Earth is done by the DSCOVR EPIC instrument, a 10 -filter spectroradiometer $(317.5-780 \mathrm{~nm})$ with a maximum resolution of $10 \times 10 \mathrm{~km}^{2}$ for $443 \mathrm{~nm}$ at the subsatellite point; the other 9 reduced-resolution channels have $18 \times 18 \mathrm{~km}^{2}$ resolution. The main difference with lowEarth-orbiting (LEO) satellites is that EPIC observes the full sunlit face of the Earth from sunrise to sunset at near-backscattering directions (the scattering angle is between $168.5^{\circ}$ and $175.5^{\circ}$ ). The frequency of EPIC observations is $68-110 \mathrm{~min}$, depending on the season (more frequently in summer, from mid-April to mid-October).

The EPIC in-flight calibration is done by comparison with well-calibrated LEO satellites: Aura OMI,
Suomi NPP OMPS for UV bands, and Terra MODIS and Aqua MODIS for visible and near-IR bands. The calibration of $\mathrm{O}_{2}$-absorbing bands are generated using the calibrated neighboring channels and EPIC lunar observations assuming that a $10-n m$ difference in wavelength leads to a difference in reflectance of only $1 \%$.

Calibrated EPIC measurements are used to produce several EPIC products including ozone, erythemal irradiance, $\mathrm{SO}_{2}$, aerosol, cloud, and vegetation properties: in particular, total ozone level and $\mathrm{SO}_{2}$ retrievals for volcanic eruptions; UV aerosol index; UV total and absorption optical depths; UV single-scattering albedo; surface spectral reflectance; aerosol optical depth in visible channels, cloud mask, cloud optical depth, and cloud height; and finally, vegetation and sunlit leaf area index and fraction of incident photosynthetically active radiation absorbed by vegetation. Some of these products are unique (e.g., the sunlit portion of the leaf area). As a matter of fact, sunlit and shaded leaves exhibit different radiative response to incident radiation, and sunlit fraction of leaf area index is the key parameter in ecosystem productivity model. Other parameters are also retrieved from LEO measurements, but a unique DSCOVR observational strategy (backscattering direction and sunrise to sunset observations) leads an innovative characterization of many of the retrieved parameters. All products are publicly available from the NASA Langley Atmospheric Science Data Center (https:// eosweb.larc.nasa.gov/project/dscovr/dscovr_table).

There are well-expected and completely unexpected discoveries made from EPIC observations. For 
example, since oxygen absorption in the B band reduces the contribution of multiple scattering (and diffuse radiation), we were able to use the $\mathrm{O}_{2} \mathrm{~B}$ band $(688 \mathrm{~nm})$ to monitor vegetation instead of a red $(680 \mathrm{~nm})$ channel without requiring an atmospheric correction. We were able to explain the bright flashes of light over land seen in EPIC RGB imagery as specular reflection of tiny ice crystals floating nearly horizontally (Marshak et al. 2017). Finally, because of EPIC's L1 orbit, we were able to estimate the erythemal irradiance and the daily variation of UV radiances from sunrise to sunset to measure skin reddening and potential sunburn from sunlight.

ACKNOWLEDGMENTS. The NASA GSFC DSCOVR project is funded by NASA Earth Science Division. We gratefully acknowledge the work by S. Taylor and B. Fisher for help with the $\mathrm{SO}_{2}$ retrievals and Marshall Sutton, Carl Hostetter, and the EPIC NISTAR project for help with EPIC data. We also would like to thank the EPIC Cloud Algorithm team, especially Dr. Gala Wind, for the contribution to the EPIC cloud products.

\section{REFERENCES}

Ackerman, S. A., A. J. Schreiner, T. J. Schmit, H. M. Woolf, J. Li, and M. Pavolonis, 2008: Using the GOES sounder to monitor upper level $\mathrm{SO}_{2}$ from volcanic eruptions. J. Geophys. Res., 113, D14S11, https://doi .org/10.1029/2007JD009622.

Bi, J., R. Myneni, A. Lyapustin, Y. Wang, T. Park, C. Chen, K. Yan, and Y. Knyazikhin, 2016: Amazon forests' response to droughts: A perspective from the MAIAC product. Remote Sens., 8, 356, https:// doi.org/10.3390/rs8040356.

Bluth, G. J. S., C. C. Schnetzler, A. J. Krueger, and L. S. Walter, 1993: The contribution of explosive volcanism to global atmospheric sulphur dioxide concentrations. Nature, 366, 327-329, https://doi .org/10.1038/366327a0.

—, W. I. Rose, I. E. Sprod, and A. J. Krueger, 1997: Stratospheric loading of sulfur from explosive volcanic eruptions. J. Geol., 105, 671-684, https://doi .org/10.1086/515972.

Bonan, G. B., S. Levis, S. Sitch, M. Vertenstein, and K. W. Oleson, 2003: A dynamic global vegetation model for use with climate models: Concepts and description of simulated vegetation dynamics. Global Change Biol., 9, 1543-1566, https://doi.org/10.1046/j.1365 -2486.2003.00681.x.

Bréon, F.-M., and B. Dubrulle, 2004: Horizontally oriented plates in clouds. J. Atmos. Sci., 61, 2888-2898, https://doi.org/10.1175/JAS-3309.1.
_- F. Maignan, M. Leroy, and I. Grant, 2002: Analysis of hot spot directional signatures measured from space. J. Geophys. Res., 107, 4282, https://doi.org/10.1029 /2001JD001094.

Brion, J., A. Chakir, D. Daumont, J. Malicet, and C. Parisse, 1993: High-resolution laboratory absorption cross section of $\mathrm{O}_{3}$. Temperature effect. Chem. Phys. Lett., 213, 610-612, https://doi.org/10.1016/0009 -2614(93)89169-I.

— - _ J. Charbonnier, D. Daumont, C. Parisse, and J. Malicet, 1998: Absorption spectra measurements for the ozone molecule in the $350-830 \mathrm{~nm}$ region. J. Atmos. Chem., 30, 291-299, https://doi .org/10.1023/A:1006036924364.

Carn, S. A., and N. A. Krotkov, 2016: Ultraviolet satellite measurements of volcanic ash. Volcanic Ash: Hazard Observation, S. Mackie et al., Eds., Elsevier, 217-231, https://doi.org/10.1016/B978-0-08-100405 $-0.00018-5$.

, A. J. Krueger, G. S. J. Bluth, S. J. Schaefer, N. A. Krotkov, I. M. Watson, and S. Datta, 2003: Volcanic eruption detection by the Total Ozone Mapping Spectrometer (TOMS) instruments: A 22-year record of sulfur dioxide and ash emissions. Volcanic Degassing, C. Oppenheimer, D. M. Pyle, and J. Barclay, Eds., Geological Society, 177-202, https:// doi.org/10.1144/GSL.SP.2003.213.01.11.

-, K. Yang, A. J. Prata, and N. A. Krotkov, 2015: Extending the long-term record of volcanic $\mathrm{SO}_{2}$ emissions with the Ozone Mapping and Profiler Suite nadir mapper. Geophys. Res. Lett., 42, https:// doi.org/10.1002/2014GL062437.

_, L. Clarisse, and A. J. Prata, 2016: Multi-decadal satellite measurements of global volcanic degassing. J. Volcanol. Geotherm. Res., 311, 99-134, https://doi .org/10.1016/j.jvolgeores.2016.01.002.

Cede, A., E. Luccini, L. Nuñez, R. D. Piacentini, and M. Blumthaler, 2002: Monitoring of erythemal irradiance in the Argentine ultraviolet network, J. Geophys. Res., 107, 4165, https://doi.org/10.1029/2001JD001206.

Channan, S., K. Collins, and W. R. Emanuel, 2014: Global mosaics of the standard MODIS land cover type data. University of Maryland and the Pacific Northwest National Laboratory, http://glcf.umd .edu/data/lc/.

Chen, J. M., J. Liu, S. G. Leblanc, R. Lacaze, and J.-L. Roujean, 2003: Multi-angular optical remote sensing for assessing vegetation structure and carbon absorption. Remote Sens. Environ., 84, 516-525, https://doi .org/10.1016/S0034-4257(02)00150-5.

—, G. Mo, J. Pisek, J. Liu, F. Deng, M. Ishizawa, and D. Chan, 2012: Effects of foliage clumping on the estimation of global terrestrial gross primary 
productivity. Global Biogeochem. Cycles, 26, GB1019, https://doi.org/10.1029/2010GB003996.

Chepfer, H., G. Brogniez, P. Goloub, F. M. Breon, and P. H. Flamant, 1999: Observations of horizontally oriented ice crystals in cirrus clouds with POLDER-1/ADEOS-1. J. Quant. Spectrosc. Radiat. Transfer, 63, 521-543, https://doi.org/10.1016/S0022 -4073(99)00036-9.

Dai, Y., R. E. Dickinson, and Y.-P. Wang, 2004: A two-bigleaf model for canopy temperature, photosynthesis, and stomatal conductance. J. Climate, 17, 2281-2299, https://doi.org/10.1175/1520-0442(2004)017<2281: ATMFCT >2.0.CO;2.

Daumont, D., J. Brion, J. Charbonnier, and J. Malicet, 1992: Ozone UV spectroscopy I: Absorption crosssections at room temperature. J. Atmos. Chem., 15, 145-155, https://doi.org/10.1007/BF00053756.

Doughty, C. E., and M. L. Goulden, 2008: Seasonal patterns of tropical forest leaf area index and $\mathrm{CO}_{2}$ exchange. J. Geophys. Res., 113, G00B06, https://doi .org/10.1029/2007JG000590.

Eckhardt, S., A. J. Prata, P. Seibert, K. Stebel, and A. Stohl, 2008: Estimation of the vertical profile of sulfur dioxide injection into the atmosphere by a volcanic eruption using satellite column measurements and inverse transport modeling. Atmos. Chem. Phys., 8, 3881-3897, https://doi.org/10.5194 /acp-8-3881-2008.

Geogdzhayev, I., and A. Marshak, 2018: Calibration of the DSCOVR EPIC visible and NIR channels using MODIS Terra and Aqua data and EPIC lunar observations. Atmos. Meas. Tech., 11, 359-368, https://doi .org/10.5194/amt-11-359-2018.

Guo, S., G. J. S. Bluth, W. I. Rose, I. M. Watson, and A. J. Prata, 2004: Re-evaluation of $\mathrm{SO}_{2}$ release of the 15 June 1991 Pinatubo eruption using ultraviolet and infrared satellite sensors. Geochem. Geophys. Geosyst., 5, Q04001, https://doi.org/10.1029/2003GC000654.

Habibi, M., 2017: Image sensors. Measurement, Instrumentation, and Sensors Handbook, 2nd ed. J. G. Webster and H. Eren, Eds., CRC Press, 1585, www.kelm.ftn.uns.ac.rs/literatura/si/pdf/ Measurement\%20Instrumentation\%20Sensors .pdf.

He, M., and Coauthors, 2013: Development of a two-leaf light use efficiency model for improving the calculation of terrestrial gross primary productivity. Agric. For. Meteor., 173, 28-39, https://doi.org/10.1016/j .agrformet.2013.01.003.

Heidinger, A. K., and M. J. Pavolonis, 2009: Gazing at cirrus clouds for 25 years through a split window. Part I: Methodology. J. Appl. Meteor. Climatol., 48, 1100-1116, https://doi.org/10.1175/2008JAMC1882.1.
Herman, J. R., 2010: Use of an improved radiation amplification factor to estimate the effect of total ozone changes on action spectrum weighted irradiances and an instrument response function. J. Geophys. Res., 115, D23119, https://doi.org/10.1029/2010JD014317.

—, P. K. Bhartia, O. Torres, C. Hsu, C. Seftor, and E. Celarier, 1997: Global distribution of UVabsorbing aerosols from Nimbus 7/TOMS data. J. Geophys. Res., 102, 16 911-16 922, https://doi .org/10.1029/96JD03680.

_, R. D. Evans, A. Cede, N. K. Abuhassan, I. Petropavlovskikh, and G. McConville, 2015: Comparison of ozone retrievals from the Pandora spectrometer system and Dobson spectrophotometer in Boulder, Colorado. Atmos. Meas. Tech., 8, 3407-3418, https:// doi.org/10.5194/amt-8-3407-2015.

— , L. Huang, R. D. McPeters, J. Ziemke, A. Cede, and K. Blank, 2018: Synoptic ozone, cloud reflectivity, and erythemal irradiance from sunrise to sunset for the whole Earth as viewed by DSCOVR spacecraft from the Earth-sun Lagrange 1 orbit. Atmos. Meas. Tech., 11, 177-194, https://doi.org/10.5194/amt-11 $-177-2018$

Hilker, T., A. I. Lyapustin, Y. Wang, F. G. Hall, C. J. Tucker, and P. J. Sellers, 2015: On the measurability of change in Amazon vegetation from MODIS. Remote Sens. Environ., 166, 233-242, https://doi .org/10.1016/j.rse.2015.05.020.

Holdaway, D., and Y. Yang, 2016a: Study of the effect of temporal sampling frequency on DSCOVR observations using the GEOS-5 nature run results (part I): Earth's radiation budget. Remote Sens., 8, 98, https:// doi.org/10.3390/rs8020098.

— and — 2016b: Study of the effect of temporal sampling frequency on DSCOVR observations using the GEOS-5 nature run results (part II): Cloud coverage. Remote Sens., 8, 431, https://doi.org/10.3390 /rs8050431.

Hughes, E. J., L. C. Sparling, S. A. Carn, and A. J. Krueger, 2012: Using horizontal transport characteristics to infer an emission height time series of volcanic $\mathrm{SO}_{2}$. J. Geophys. Res., 117, D18307, https:// doi.org/10.1029/2012JD017957.

Jaross, G., and Coauthors, 2014: OMPS Limb Profiler instrument performance assessment.J. Geophys. Res., 119, 4399-4412, https://doi.org/10.1002/2013JD020482.

Jethva, H., O. Torres, L. Remer, and P. K. Bhartia, 2013: A color ratio method for simultaneous retrieval of aerosol and cloud optical thickness of above-cloud absorbing aerosols from passive sensors: Application to MODIS measurements. IEEE Trans. Geosci. Remote Sens., 51, 3862-3870, https://doi.org/10.1109 /TGRS.2012.2230008. 
King, M. D., Y. J. Kaufman, W. P. Menzel, and D. Tandre, 1992: Remote sensing of cloud, aerosol, and water vapor properties from the Moderate Resolution Imaging Spectroradiometer (MODIS). IEEE Trans. Geosci. Remote Sens., 30, 2-27, https://doi.org/10.1109 /36.124212.

Knapp, K. R., 2002: Quantification of aerosol signal in GOES 8 visible imagery over the United States. J. Geophys. Res., 107, 4426, https://doi.org/10.1029 /2001JD002001.

Knyazikhin, Y., M. A. Schull, L. Xu, R. B. Myneni, and A. Samanta, 2011: Canopy spectral invariants. Part 1: A new concept in remote sensing of vegetation. J. Quant. Spectrosc. Radiat. Transf., 112, 727-735, https://doi.org/10.1016/j.jqsrt.2010.06.014.

— , and Coauthors, 2013: Hyperspectral remote sensing of foliar nitrogen content. Proc. Natl. Acad. Sci. USA, 110, E185-E192, https://doi.org/10.1073 /pnas.1210196109.

Koelemeijer, R. B. A., P. Stammes, J. W. Hovenier, and J. F. de Haan, 2001: A fast method for retrieval of cloud parameters using oxygen A band measurements from the Global Ozone Monitoring Experiment. J. Geophys. Res., 106, 3475-3490, https://doi .org/10.1029/2000JD900657.

Korolev, A., G. A. Isaac, and J. Hallett, 2000: Ice particle habits in stratiform clouds. Quart. J. Roy. Meteor. Soc., 126, 2873-2902, https://doi.org/10.1002/qj .49712656913 .

Krotkov, N. A., and Coauthors, 1999a: Comparison of TOMS and AVHRR volcanic ash retrievals from the August 1992 eruption of Mt. Spurr. Geophys. Res. Lett., 26, 455-458, https://doi.org/10.1029/1998GL900278.

— D. E. Flittner, A. J. Krueger, A. Kostinski, C. Riley, W. Rose, and O. Torres, 1999b: Effect of particle nonsphericity on satellite monitoring of drifting volcanic ash clouds. J. Quant. Spectrosc. Radiat. Transf., 63, 613630, https://doi.org/10.1016/S0022-4073(99)00041-2.

_, M. R. Schoeberl, G. A. Morris, S. Carn, and K. Yang, 2010: Dispersion and lifetime of the $\mathrm{SO}_{2}$ cloud from the August 2008 Kasatochi eruption. J. Geophys. Res., 115, D00L20, https://doi.org/10.1029 /2010JD013984.

Krueger, A. J., 1983: Sighting of El Chichón sulfur dioxide clouds with the Nimbus 7 Total Ozone Mapping Spectrometer. Science, 220, 1377-1378, https:/doi .org/10.1126/science.220.4604.1377.

— , L. S. Walter, P. K. Bhartia, C. C. Schnetzler, N. A. Krotkov, I. Sprod, and G. J. S. Bluth, 1995: Volcanic sulfur dioxide measurements from the Total Ozone Mapping Spectrometer instruments. J. Geophys. Res., 100, 14057-14076, https://doi.org/10 .1029/95JD01222.
— S. J. Schaefer, N. Krotkov, G. Bluth, and S. Baker, 2000: Ultraviolet remote sensing of volcanic emissions. Remote Sensing of Active Volcanism, Geophys. Monogr., Vol. 116, Amer. Geophys. Union, 25-43.

Kuusk, A., 1991: The hot spot effect in plant canopy reflectance. Photon-Vegetation Interactions: Applications in Plant Physiology and Optical Remote Sensing, R. B. Myneni and J. Ross, Eds., SpringerVerlag, 139-159.

Li, C., N. A. Krotkov, S. Carn, Y. Zhang, R. J. D. Spurr, and J. Joiner, 2017: New-generation NASA Aura Ozone Monitoring Instrument (OMI) volcanic $\mathrm{SO}_{2}$ dataset: Algorithm description, initial results, and continuation with the Suomi-NPP Ozone Mapping and Profiler Suite (OMPS). Atmos. Meas. Tech., 10, 445-458, https://doi.org/10.5194/amt-10-445-2017.

Lucht, W., C. B. Schaaf, and A. H. Strahler, 2000: An algorithm for the retrieval of albedo from space using semiempirical BRDF models. IEEE Trans. Geosci. Remote Sens., 38, 977-998, https://doi .org/10.1109/36.841980.

Lyapustin, A., Y. Wang, I. Laszlo, R. Kahn, S. Korkin, L. Remer, R. Levy, and J. S. Reid, 2011: MultiAngle Implementation of Atmospheric Correction (MAIAC): 2. Aerosol algorithm. J. Geophys. Res., 116, D03211, https://doi.org/10.1029/2010JD014986.

,,$-- \ldots$, T. Hilker, F. Hall, P. Sellers, J. Tucker, and S. Korkin, 2012: Multi-Angle Implementation of Atmospheric Correction for MODIS (MAIAC). 3: Atmospheric correction. Remote Sens. Environ., 127, 385-393, https://doi.org/10.1016/j.rse.2012.09.002.

Malicet, J., D. Daumont, J. Charbonnier, C. Chakir, A. Parisse, and J. Brion, 1995: Ozone UV spectroscopy. II: Absorption cross-sections and temperature dependence. J. Atmos. Chem., 21, 263-273, https://doi .org/10.1007/BF00696758.

Marshak, A., and Y. Knyazikhin, 2017: The spectral invariant approximation within canopy radiative transfer to support the use of the EPIC/DSCOVR oxygen B-band for monitoring vegetation. J. Quant. Spectrosc. Radiat. Transfer, 191, 7-12, https://doi.org /10.1016/j.jqsrt.2017.01.015.

— , T. Varnai, and A. Kostinski, 2017: Terrestrial glint seen from deep space: Oriented ice crystals detected from the Lagrangian point. Geophys. Res. Lett., 44, 5197-5202, https://doi.org/10.1002/2017GL073248.

McKinley, A. F., and B. L. Diffey, 1987: A reference action spectrum for ultraviolet induced erythema in human skin. Human Exposure to Ultraviolet Radiation: Risks and Regulations, W. R. Passchier and B. F. M. Bosnjakovic, Eds., Elsevier, 83-87.

Mercado, L. M., N. Bellouin, S. Sitch, O. Boucher, C. Huntingford, M. Wild, and P. M. Cox, 2009: Impact of 
changes in diffuse radiation on the global land carbon sink. Nature, 458, 1014-1017, https://doi.org/10 .1038 /nature07949.

Meyer, K., Y. Yang, and S. Platnick, 2016: Uncertainties in cloud phase and optical thickness retrievals from the Earth Polychromatic Imaging Camera (EPIC). Atmos. Meas. Tech., 9, 1785-1797, https://doi .org/10.5194/amt-9-1785-2016.

National Research Council, 2007: Earth Science and Applications from Space: National Imperatives for the Next Decade and Beyond. The National Academies Press, 454 pp., https://doi.org/10.17226/11820.

Nilson, T., 1991: Approximate analytical methods for calculating the reflection functions of leaf canopies in remote sensing. Photon-Vegetation Interactions: Applications in Plant Physiology and Optical Remote Sensing, R. B. Myneni and J. Ross, Eds., SpringerVerlag, 161-190.

Noel, V., and H. Chepfer, 2004: Study of ice crystal orientation in cirrus clouds based on satellite polarized radiance measurements. J. Atmos. Sci., 61, 2073-2081, https://doi.org/10.1175/1520-0469(2004)061<2073: SOICOI $>2.0 . \mathrm{CO} ; 2$.

- , and — 2010: A global view of horizontally oriented crystals in ice clouds from Cloud-Aerosol Lidar and Infrared Pathfinder Satellite Observation (CALIPSO). J. Geophys. Res., 115, D00H23, https:// doi.org/10.1029/2009JD012365.

Norman, J. M., 1982: Simulation of microclimates. Biometeorology in Integrated Pest Management, Elsevier, 65-99.

Ohtake, M., and Coauthors, 2010: Deriving the absolute reflectance of lunar surface using SELENE (Kaguya) multiband imager data. Space Sci. Rev., 154, 57-77, https://doi.org/10.1007/s11214-010-9689-0.

— ments 3: Spectral reflectance. Icarus, 226, 364-374, https://doi.org/10.1016/j.icarus.2013.05.010.

Parkinson, C. L., 2003: Aqua: An Earth-observing satellite mission to examine water and other climate variables. IEEE Trans. Geosci. Remote Sens., 41, 173-183, https://doi.org/10.1109/TGRS.2002 .808319 .

Pavolonis, M., A. Heidinger, and J. Sieglaff, 2013: Automated retrievals of volcanic ash and dust cloud properties from upwelling infrared measurements. J. Geophys. Res. Atmos., 118, 1436-1458, https://doi.org /10.1002/jgrd.50173.

Platnick, S., and Coauthors, 2017: The MODIS cloud optical and microphysical products: Collection 6 updates and examples from Terra and Aqua. IEEE Trans. Geosci. Remote Sens., 55, 502-525, https://doi .org/10.1109/TGRS.2016.2610522.
Prata, A. J., 1989: Observations of volcanic ash clouds in the 10-12 mm window using AVHRR/2 data. Int. J. Remote Sens., 10, 751-776, https://doi.org/10.1080 /01431168908903916.

— , and C. Bernardo, 2007: Retrieval of volcanic $\mathrm{SO}_{2}$ column abundance from Atmospheric Infrared Sounder data. J. Geophys. Res., 112, D20204, https:// doi.org/10.1029/2006JD007955.

_ , and J. Kerkmann, 2007: Simultaneous retrieval of volcanic ash and $\mathrm{SO}_{2}$ using MSG-SEVIRI measurements. Geophys. Res. Lett., 34, L05813, https://doi.org/10.1029 /2006GL028691.

_ - and G. Prata, 2015: Remote sensing of volcanic ash and sulfur dioxide. Volcanism and Global Environmental Change, A. Schmidt and K. Fristad, Eds., Cambridge University Press, 97-114, https://doi .org/10.1017/CBO9781107415683.010.

—, W. I. Rose, S. Self, and D. M. O’Brien, 2003: Global, long-term sulphur dioxide measurements from TOVS data: A new tool for studying explosive volcanism and climate. Volcanism and the Earth's Atmosphere, Geophys. Monogr., Vol. 139, Amer. Geophys. Union, 75-92.

— , G. J. G. Bluth, C. Werner, V. Realmuto, S. Carn, and M. Watson, 2015: Remote sensing of gas emissions from volcanoes. Monitoring Volcanoes in the North Pacific, Springer, 145-186.

Qin, W., N. S. Goel, and B. Wang, 1996: The hotspot effect in heterogeneous vegetation canopies and performances of various hotspot models. Remote Sens. Rev., 14, 283-332, https://doi.org/10.1080 /02757259609532323.

Realmuto, V. J., 2000: The potential use of Earth Observing System data to monitor the passive emission of sulfur dioxide from volcanoes. Remote Sensing of Active Volcanism, Geophys. Monogr., Vol. 116, Amer. Geophys. Union, 101-115.

Ross, J. K., and A. L. Marshak, 1988: Calculation of canopy bidirectional reflectance using the Monte Carlo method. Remote Sens. Environ., 24, 213-225, https://doi.org/10.1016/0034-4257(88)90026-0.

Sassen, K., and S. Benson, 2001: A midlatitude cirrus cloud climatology from the facility for atmospheric remote sensing. Part II: Microphysical properties derived from lidar depolarization. J. Atmos. Sci., 58, 2103-2112, https:/doi.org/10.1175/1520-0469(2001)058<2103: AMCCCF>2.0.CO;2.

Scarino, B. R., D. R. Doelling, P. Minnis, A. Gopalan, T. Chee, R. Bhatt, C. Lukashin, and C. O. Haney, 2016: A web-based tool for calculating spectral band difference adjustment factors derived from SCIAMACHY hyperspectral data, IEEE Trans. Geosci. Remote Sens., 54, 2529-2542. 
Schmit, T. J., J. Li, J. J. Gurka, M. D. Goldberg, K. J. Schrab, J. Li, and W. F. Feltz, 2008: The GOES-R Advanced Baseline Imager and the continuation of current sounder products. J. Appl. Meteor. Climatol., 47, 2696-2711, https://doi.org/10.1175/2008JAMC1858.1.

—, P. Griffith, M. M. Gunshor, J. M. Daniels, S. J. Goodman, and W. J. Lebair, 2017: A closer look at the ABI on the GOES-R series. Bull. Amer. Meteor. Soc., 98, 681-698, https://doi.org/10.1175/BAMS -D-15-00230.1.

Stenberg, P., 1998: Implications of shoot structure on the rate of photosynthesis at different levels in a coniferous canopy using a model incorporating grouping and penumbra. Funct. Ecol., 12, 82-91, https://doi .org/10.1046/j.1365-2435.1998.00169.x.

—, M. Mõttus, and M. Rautiainen, 2016: Photon recollision probability in modelling the radiation regime of canopies-A review. Remote Sens. Environ., 183, 98-108, https://doi.org/10.1016/j.rse.2016.05.013.

Stephens, G. L., S. C. Tsay, P. W. Stackhouse Jr., and P. J. Flateau, 1990: The relevance of the microphysical and radiative properties of cirrus clouds to the climate and climatic feedback. J. Atmos. Sci., 47, 1742-1753, https://doi.org/10.1175/1520-0469(1990)047<1742: TROTMA>2.0.CO;2.

Torres, O., P. K. Bhartia, J. R. Herman, and Z. Ahmad, 1998: Derivation of aerosol properties from satellite measurements of backscattered ultraviolet radiation: Theoretical basis. J. Geophys. Res., 103, 17 099-17 110, https://doi.org/10.1029/98JD00900.

_, A. Tanskanen, B. Veihelman, C. Ahn, R. Braak, P. K. Bhartia, P. Veefkind, and P. Levelt, 2007: Aerosols and surface UV products from OMI observations: An overview. J. Geophys. Res., 112, D24S47, https://doi.org/10.1029/2007JD008809.

—, H. Jethva, and P. K. Bhartia, 2012: Retrieval of aerosol optical depth above clouds from OMI observations: Sensitivity analysis and case studies. J. Atmos. Sci., 69, 1037-1053, https://doi.org/10.1175 /JAS-D-11-0130.1.

—, C. Ahn, and Z. Chen, 2013: Improvements to the OMI near UV aerosol algorithm using A-train CALIOP and AIRS observations. Atmos. Meas. Tech., 6, 3257-3270, https://doi.org/10.5194/amt-6-3257-2013.
Tucker, C. J., 1979: Red and photographic infrared linear combination for monitoring vegetation. Remote Sens. Environ., 8, 127-150, https://doi.org/10.1016/0034 $-4257(79) 90013-0$.

Ustin, S. L., 2013: Remote sensing of canopy chemistry. Proc. Natl. Acad. Sci. USA, 110, 804-805, https://doi .org/10.1073/pnas.1219393110.

Wang, S., R. Grant, D. Verseghy, and T. Black, 2001: Modelling plant carbon and nitrogen dynamics of a boreal aspen forest in CLASS-the Canadian Land Surface Scheme. Ecol. Modell., 142, 135-154, https:// doi.org/10.1016/S0304-3800(01)00284-8.

Wargan, K., G. Labow, S. Frith, S. Pawson, N. Livesey, and G. Partyka, 2017: Evaluation of the ozone fields in NASA's MERRA-2 reanalysis. J. Climate, 30, 29612988, https://doi.org/10.1175/JCLI-D-16-0699.1.

Wen, S., and W. I. Rose, 1994: Retrieval of particle sizes and masses in volcanic clouds using AVHRR bands 4 and 5. J. Geophys. Res., 99, 5421-5431, https://doi .org/10.1029/93JD03340.

$\mathrm{Xu}, \mathrm{X}$., and Coauthors, 2017: Passive remote sensing of altitude and optical depth of dust plumes using the oxygen A and B bands: First results from EPIC/ DSCOVR at Lagrange-1 point. Geophys. Res. Lett., 44, 7544-7554, https://doi.org/10.1002/2017GL073939.

Yang, B., and Coauthors, 2017: Estimation of leaf area index and its sunlit portion from DSCOVR EPIC data: Theoretical basis. Remote Sens. Environ., 198, 69-84, https://doi.org/10.1016/j.rse.2017.05.033.

Yang, P., H.-L. Wei, B. A. Baum, H.-L. Huang, A. J. Heymsfield, Y. X. Hu, B.-C. Gao, and D. D. Turner, 2003: The spectral signature of mixed-phase clouds composed of nonspherical ice crystals and spherical liquid droplets in the terrestrial window region. $J$. Quant. Spectrosc. Radiat. Transfer, 79-80, 1171-1188, https://doi.org/10.1016/S0022-4073(02)00348-5.

Yang, Y., A. Marshak, J. Mao, A. Lyapustin, and J. Herman, 2013: A method of retrieving cloud top height and cloud geometrical thickness with oxygen A and B bands for the Deep Space Climate Observatory (DSCOVR) mission: Radiative transfer simulations. J. Quant. Spectrosc. Radiat. Trans., 122, 141-149, https://doi.org/10.1016/j.jqsrt.2012 .09 .017 . 